\title{
The Pagami Creek smoke plume after long-range transport to the upper troposphere over Europe - aerosol properties and black carbon mixing state
}

\author{
F. Dahlkötter ${ }^{1}$, M. Gysel ${ }^{2}$, D. Sauer ${ }^{1,3}$, A. Minikin ${ }^{1}$, R. Baumann ${ }^{1}$, P. Seifert ${ }^{4}$, A. Ansmann ${ }^{4}$, M. Fromm ${ }^{5}$, C. Voigt ${ }^{1,6}$, \\ and B. Weinzierl ${ }^{1,3}$ \\ ${ }^{1}$ Deutsches Zentrum für Luft- und Raumfahrt (DLR), Institut für Physik der Atmosphäre, Oberpfaffenhofen, Germany \\ ${ }^{2}$ Paul Scherrer Institute, Laboratory of Atmospheric Chemistry, Villigen PSI, Switzerland \\ ${ }^{3}$ Ludwig-Maximilians-Universität München, Meteorologisches Institut, München, Germany \\ ${ }^{4}$ Leibniz-Institut für Troposphärenforschung, Leipzig, Germany \\ ${ }^{5}$ Naval Research Laboratory, Washington, D.C., USA \\ ${ }^{6}$ Johannes Gutenberg-Universität Mainz, Institut für Physik der Atmosphäre, Mainz, Germany
}

Correspondence to: B. Weinzierl (bernadett.weinzierl@dlr.de)

Received: 23 August 2013 - Published in Atmos. Chem. Phys. Discuss.: 5 November 2013

Revised: 5 March 2014 - Accepted: 14 March 2014 - Published: 20 June 2014

\begin{abstract}
During the CONCERT 2011 field experiment with the DLR research aircraft Falcon, an enhanced aerosol layer with particle linear depolarization ratios of $6-8 \%$ at $532 \mathrm{~nm}$ was observed at altitudes above $10 \mathrm{~km}$ over northeast Germany on 16 September 2011. Dispersion simulations with HYSPILT suggest that the elevated aerosol layer originated from the Pagami Creek forest fire in Minnesota, USA, which caused pyro-convective uplift of particles and gases. The 34 day-old smoke plume had high total refractory black carbon (rBC) mass concentrations of $0.03-0.35 \mu \mathrm{g} \mathrm{m}^{-3}$ at standard temperature and pressure (STP) with $\mathrm{rBC}$ mass equivalent diameter predominantly smaller than $130 \mathrm{~nm}$. Assuming a core-shell particle structure, the $\mathrm{BC}$ cores exhibit very thick (median: 105-136 nm) BC-free coatings. A large fraction of the BC-containing particles disintegrated into a BCfree fragment and a $\mathrm{BC}$ fragment while passing through the laser beam of the Single Particle Soot Photometer (SP2). In this study, the disintegration is a result of very thick coatings around the $\mathrm{BC}$ cores. This is in contrast to a previous study in a forest-fire plume, where it was hypothesized to be a result of $\mathrm{BC}$ cores being attached to a $\mathrm{BC}$-free particle. For the high-altitude forest-fire aerosol layer observed in this study, increased mass specific light-absorption cross sections of $\mathrm{BC}$ can be expected due to the very thick coatings around the $\mathrm{BC}$ cores, while this would not be the case
\end{abstract}

for the attached-type morphology. We estimate the BC mass import from the Pagami Creek forest fire into the upper troposphere/lower stratosphere (UTLS) region (best estimate: $25 \mathrm{Mg} \mathrm{rBC}$ ). A comparison to black carbon emission rates from aviation underlines the importance of pyro-convection on the BC load in the UTLS region. Our study provides detailed information on the microphysics and the mixing state of $\mathrm{BC}$ in the forest-fire aerosol layer in the upper troposphere that can be used to better understand and investigate the radiative impact of such upper tropospheric aerosol layers.

\section{Introduction}

Light-absorbing aerosol species, such as black carbon (BC), contribute to a large part to the positive radiative forcing of aerosols (Jacobson, 2001). Recent modeling studies suggest that $\mathrm{BC}$ is the second strongest source to current global warming after $\mathrm{CO}_{2}$ (Ramanathan and Carmichael, 2008) because it is the dominant solar-radiation-absorbing component in the visible spectrum in the atmosphere. A comprehensive scientific assessment of the role of $\mathrm{BC}$ in the climate system is given in Bond et al. (2013). The terminology used in the literature for carbonaceous particles from combustion emissions is often ambiguous (Petzold et al., 2013). Here we 
use the term "BC" exclusively for the most refractory and light-absorbing component of carbonaceous combustion particles, which is essentially pure carbon, not including organic carbon, brown carbon or inorganic aerosol components. The term "BC-containing" particle is used for referring to combustion particles with some $\mathrm{BC}$ content. A particle is classified as a "BC-free" particle, if the Single Particle Soot Photometer (SP2) does not detect any BC in the particle, which does not exclude the presence of a small amount of $\mathrm{BC}$ below the lower detection limit of the SP2 $(\sim 0.5 \mathrm{fg} \mathrm{BC}$ in a particle). Furthermore, we use the more specific term refractory black carbon (rBC; see Petzold et al., 2013), whenever we refer to quantitative measurements of the $\mathrm{rBC}$ mass (or quantities inferred from $\mathrm{rBC}$ mass measurements) with the SP2 (Schwarz et al., 2006).

Besides BC, other light-absorbing materials such as brown carbon, a light-absorbing organic carbon (OC), can contribute significantly to light absorption (e.g. Andreae and Gelencser, 2006; Moosmüller et al., 2009). The largest source of primary carbonaceous fine particles in the global troposphere is anthropogenically- and naturally-occurring biomass burning defined as the sum of all open natural and anthropogenic combustion processes using non-fossilized vegetative or organic fuels (e.g. Akagi et al., 2011). Biomass burning has a major impact on the radiation budget of the atmosphere (Knorr et al., 2012). Diehl et al. (2012) estimate the global $\mathrm{BC}$ emissions from biomass burning as 1.87.0 Tg per year, while OC emissions range from $14-57 \mathrm{Tg}$ per year. Biomass-burning emissions can be transported to the free troposphere and even into the stratosphere by, for example, pyro-convection, as it was observed for a North American forest fire by, for example, Jost et al. (2004) ${ }^{1}$. There elevated aerosol layers may form. Biomass-burning aerosol layers are often transported over long distances on hemispheric scales (e.g., Damoah et al., 2004; Mattis et al., 2008; Ramanathan and Feng, 2009; Petzold et al., 2007). In this study we define an elevated aerosol layer as a vertically extended layer situated above the planetary boundary layer, containing aerosol particles. Such long-range transport of biomass-burning emissions was previously measured and reported by, for example, Fiebig et al. (2003), Petzold et al. (2007), Real et al. (2007), Tesche et al. (2009), Quennehen et al. (2011), Weinzierl et al. (2011) and Quennehen et al. (2012). Barnaba et al. (2011) estimate for the 6 year period, 2002-2007, that up to $35 \%$ (maxima in April and in summer) of the aerosol optical thickness of the European fine particle fraction $\left(D_{\mathrm{opt}}<1 \mu \mathrm{m}\right)$ is attributable to wildfire emissions, including long-range transport from North America. Based on ten years of ground-based multi-wavelength Raman lidar (light detection and ranging) observations, Mattis et al. (2008) observed free-tropospheric aerosol layers above

\footnotetext{
"In this study, the general term "biomass-burning aerosol" is used if utilized in referenced studies while "forest-fire aerosol" is used for the case treated in this study.
}

the continental boundary layer of central Europe in $43 \%$ of their measurements, with a maximum from June to August. In $19 \%$ of their measurements, they found forest-fire smoke advected from Canada and anthropogenic pollution advected from urban areas of the USA and Canada.

During transport, the biomass-burning plumes can mix with other aerosols (e.g., Ramanathan and Carmichael, 2008; Tesche et al., 2009; Petzold et al., 2011; Weinzierl et al., 2011). Depending on the composition and altitude, and albedo of the underlying surface, these layers can impact the radiative budget and may have cooling or warming effects on different parts of the atmosphere. In particular, BC in elevated aerosol layers absorbs incoming solar radiation effectively and transforms it into thermal radiation (Moosmüller et al., 2009). In this context, the mixing state of BCcontaining particles is important because coatings of lightscattering material can enhance the absorption of the $\mathrm{BC}$ core due to the so-called "lensing effect" and can thus amplify the heating potential of BC-containing aerosol particles on the surrounding air (Bauer et al., 2010; Shiraiwa et al., 2010). Enhancements of the absorption by at least $30 \%$ (Schwarz et al., 2008b) up to $100 \%$ have been calculated for thickly coated particles with an optical particle diameter to core diameter $\left(D_{\mathrm{opt}} / D_{\mathrm{rBC}}\right)$ ratio of 2 (Shiraiwa et al., 2010). However, Cappa et al. (2012) report a significant difference in the coatings' absorption enhancement in ambient observations versus laboratory measurements and model results. Thus, the understanding of the absorption enhancement and the radiative forcing by mixed atmospheric BC is still incomplete and needs further investigation. Aside from this idealized internal shell-core mixture of particles, more complex structures of $\mathrm{BC}$ particles and $\mathrm{BC}$-free materials exist in nature (e.g., Sedlacek et al., 2012). Semi-external mixtures such as particles attached to each other or near-surface BC cores can be observed in the atmosphere as well (Mishchenko et al., 2004; Liu and Mishchenko, 2007). More information about particle mixing is given in Buseck and Posfai (1999), Posfai et al. (2003), and Posfai et al. (2004).

Although complicated mixing structures are observed in nature, most modeling studies assume homogeneously mixed or idealized core-shell morphologies as a basis for radiative transfer calculations. Only some recent model developments implement the particle mixing state (e.g., Aquila et al., 2011). In addition to a changed impact on the radiative aerosol properties, the structure of mixed particles, for example, internal mixing of a $\mathrm{BC}$ core with organic or inorganic aerosol components, might have an influence on the activation of $\mathrm{BC}$ particles to form cloud droplets in warmer regimes, possibly leading to an increased $\mathrm{BC}$ wet deposition and a related decrease in $\mathrm{BC}$ residence times. Furthermore, the ice-nucleation efficiency of the particle and thus the associated indirect climate effect of these aerosols may be impacted (Hoose and Möhler, 2012).

Although recently more studies focus on airborne in situ measurements of the vertical distribution of $\mathrm{BC}$ in the 
troposphere (e.g., McMeeking et al., 2010; Schwarz et al., 2010), so far, processes concerning light-absorbing aerosol layers and their impact on the radiation budget are only insufficiently quantified and characterized. One reason for this deficiency is the sparseness of airborne in situ measurements in elevated aerosol layers. In this study, we present airborne in situ data of elevated aerosol layers observed with the Deutsches Zentrum für Luft- und Raumfahrt (DLR) research aircraft Falcon-20E in the framework of Contrail and Cirrus Experiment 2011 (CONCERT 2011) over central Europe in September 2011 (Voigt et al., 2014). In particular, we focus on the investigation of an elevated forest-fire aerosol layer observed on 16 September 2011 over northeast Germany, originating from the Pagami Creek forest-fire in North America.

The present study is organized as follows: in Sect. 2, we give an overview of the CONCERT research flights and describe the instrument calibration and data analysis procedures with focus on the SP2. In Sect. 3, we show the results of our measurements in the Pagami Creek forest fire including a detailed analysis of microphysical and optical aerosol properties, vertical and horizontal extension of the Pagami Creek plume and use dispersion simulations with HYSPLIT for source attribution. In Sect. 4, we compare the observations made on 16 September 2011 with other measurements in elevated aerosol layers during CONCERT 2011 and with the literature. Furthermore, we discuss the morphology and potential disintegration of the observed $\mathrm{rBC}$ particles on the basis of our SP2 measurements. Finally, we present an estimate on the black carbon mass import into the UTLS by the Pagami Creek fire and compare it with the BC import into the UTLS by aviation.

\section{Material and methods}

\subsection{Research flights and instrumentation}

The main focus of the CONCERT 2011 mission, the followup mission of CONCERT 2008 (Voigt et al., 2010), was the measurement of microphysical and optical properties of contrail cirrus (Voigt et al., 2011; Schumann et al., 2011a) and natural cirrus in order to investigate their climate impact (Kübbeler et al., 2011; Schumann et al., 2013; Jeßberger et al., 2013). Here we focus on the serendipitous observation of an enhanced aerosol layer in the upper troposphere/lower stratosphere (UTLS) region, originating from the Pagami Creek forest fire in Minnesota, USA. During CONCERT 2011, the DLR Falcon research aircraft was based in Oberpfaffenhofen, Germany, and performed 11 research flights between 7 September and 30 September 2011. Most of the flights were conducted over Germany, with additional landings in Norway and Italy. Instruments from DLR and the Universities of Mainz and Clermont-Ferrand were operated onboard the DLR Falcon. The following ba- sic aerosol parameters were measured: particle size distribution, $\mathrm{rBC}$ mass concentration, $\mathrm{rBC}$ core size distribution, mixing state of $\mathrm{rBC}$-free and $\mathrm{rBC}$-containing particles, light scattering coefficient and light absorption coefficient. In addition, instruments for trace gases were deployed on the Falcon. Most of them are described in Voigt et al. (2010) and the references therein. In the following, we only describe the instruments used in this study.

In the past decades BC measurements in the atmosphere were conducted predominantly with filter-based instruments. In this study, the more recently introduced Single Particle Soot Photometer (SP2; Stephens et al., 2003) was applied to obtain information about the $\mathrm{rBC}$ mass concentration as well as the mixing state and coating thickness of rBCcontaining particles. The SP2 determines the optical size and the rBC mass of single rBC-containing particles, using lightscattering and laser-induced incandescence methods, respectively (Schwarz et al., 2006). More details about the functional principles, calibration and data analysis approaches of the SP2 will be summarized in Sect. 2.2.

To obtain information on the entire aerosol size distribution, measurements from five condensation particle counters (two modified TSI Condensation Particle Counters (CPC; models 3010 and 3760A) and three Condensation Particle Size Analyzers (CPSA; built by DLR) set to different lower cut-off diameters $(4 \mathrm{~nm}, 10 \mathrm{~nm}, 14 \mathrm{~nm}))$ are combined with optical sizing measurements from the SP2 and a wingmounted Forward Scattering Spectrometer Probe (FSSP300 ). One of the CPCs was operated on 16 September behind a thermal denuder, heating the aerosol to $255^{\circ} \mathrm{C}$ to measure non-volatile particles. Table 1 summarizes the aerosol parameters and the size ranges covered by the different aerosol in situ instruments used in this study.

\subsection{Instrument calibration and data analysis}

In the SP2, a concentric-nozzle jet system is used to direct the aerosol sample flow through a high-intensity continuouswave intra-cavity laser beam $(\lambda=1064 \mathrm{~nm})$ and four different detectors are used to characterize individual particles with $100 \%$ detection efficiency within the respective detection limits (see Table 1). The response curves of four detectors for each particle are recorded for $44 \mu \mathrm{s}$ with a temporal resolution of $0.2 \mu$ s.

A broadband incandescence detector (BID) and a narrowband incandescence detector (NID), both standard detectors implemented in the SP2 by the manufacturer, are used to detect the thermal radiation emitted by light-absorbing and refractory particles heated to incandescence in the $300-800 \mathrm{~nm}$ and $630-800 \mathrm{~nm}$ wavelengths bands, respectively. The peak intensity of the thermal radiation is typically reached at the vaporization temperature of the most refractory particle component. The incandescence signals from atmospheric aerosol particles normally originate from $\mathrm{rBC}$ and the peak height of the incandescence signal is proportional to the $\mathrm{rBC}$ mass 
Table 1. Size ranges of the aerosol instrumentation onboard the Falcon aircraft considered in this study during the flights on 16 September 2011. The first column displays the name of the instrument, the second column the measured property, and the third column the respective size range. CPC, Condensation Particle Counter; CPSA, Condensation Particle Size Analyzer; SP2, Single Particle Soot Photometer; LSD, light scattering detector; BID, broadband incandescence detector; NID, narrowband incandescence detector; PSD, position sensitive detector; FSSP 300, Forward Scattering Spectrometer Probe.

\begin{tabular}{|c|c|c|}
\hline Instrument & Property & Size/mass range \\
\hline CPC/CPSA & integral number concentration ${ }^{1}$ of ultrafine particles & $0.004 \mu \mathrm{m}<D_{\text {opt }}<D_{\text {cutoff }}$ \\
\hline \multirow[t]{11}{*}{ SP2 } & LSD & \\
\hline & single particle optical diameter of rBC-free particles & $0.14 \mu m<D_{\mathrm{opt}}<0.29 \mu \mathrm{m}$ \\
\hline & ambient number size distribution of $\mathrm{rBC}$-free particles & $0.14 \mu m<D_{\mathrm{opt}}<0.29 \mu \mathrm{m}$ \\
\hline & BID, NID & \\
\hline & single particle rBC mass & $0.5 \mathrm{fg}<m_{\mathrm{rBC}}<80.3 \mathrm{fg}$ \\
\hline & ambient $\mathrm{rBC}$ mass size distribution & $0.08 \mu m<D_{\mathrm{rBC}}<0.44 \mu \mathrm{m}$ \\
\hline & LSD, BID, NID, PSD & \\
\hline & Leading-edge-only (LEO) fit: & \\
\hline & single particle optical diameter of & $\sim 0.15 \mu \mathrm{m}<D_{\mathrm{opt}}<\sim 0.55 \mu \mathrm{m}$ \\
\hline & $\mathrm{rBC}$-free and $\mathrm{rBC}$-containing particles & (cut-offs dependent on \\
\hline & coating thickness of $\mathrm{rBC}$-containing particles & \\
\hline \multirow[t]{2}{*}{ FSSP-300 } & ambient size distribution $^{2}$ & nominal size range \\
\hline & & $0.3 \mu m<D_{\text {opt }}<30 \mu \mathrm{m}$ \\
\hline $\begin{array}{l}\text { Falcon standard } \\
\text { instrumentation }\end{array}$ & $T, p, \mathrm{RH}, 3$-D-wind velocity & \\
\hline
\end{tabular}

in a particle, independent of particle morphology or coatings with non-refractory aerosols components (Schwarz et al., 2006; Moteki and Kondo, 2007, 2010). The BID and NID are empirically calibrated using the fullerene soot batch from Alfa Aesar (stock \#40971, lot \#FS12S011), which has been shown to provide equal incandescence detector response per mass as atmospheric rBC (Moteki and Kondo, 2010; Laborde et al., 2012a), and which is recommended as the most suitable SP2 calibration material for atmospheric rBC applications (Baumgardner et al., 2012). The mass equivalent diameter of the rBC cores, $D_{\mathrm{rBC}}$, is calculated from the measured $\mathrm{rBC}$ mass, assuming void-free spherical $\mathrm{rBC}$ cores and an $\mathrm{rBC}$ material density of $1800 \mathrm{~kg} \mathrm{~m}^{-3}$. The applied design of the SP2 and the gain settings used for the CONCERT 2011 field experiment limit rBC core measurements and the $\mathrm{rBC}$ mass size distribution to a range of approximately $80<D_{\mathrm{rBC}}<440 \mathrm{~nm}\left(0.5<m_{\mathrm{rBC}}<80.3 \mathrm{fg}\right.$; see also Table 1). The contribution of $\mathrm{rBC}$ cores outside the detection range of the SP2 to the integral total $\mathrm{rBC}$ mass concentration was accounted for by extrapolating the measured $\mathrm{rBC}$ mass size distribution with a log-normal fit (see schematic in Fig. 1a). For the CONCERT 2011 data set, the log-normal distribution was fitted to the measured $\mathrm{rBC}$ core mass size distribution in the range $80-250 \mathrm{~nm}$ (the size range between $250 \mathrm{~nm}$ and the upper detection limit was not considered for fitting in order to avoid fitting biases from insufficient counting statistics in this size range). This approach provides re- liable results as the mass size distributions (which are generally of log-normal shape) peak in the measured size range, i.e., the mass median diameter (MMD) falls into the measured size range. In our case, this extrapolation accounts for $20 \%$ of the total rBC mass.

A light scattering detector (LSD) detects elastically scattered light at $1064 \mathrm{~nm}$ wavelength. The LSD signal is used for the optical sizing of the particles. Assuming $\mathrm{rBC}$ as the main light-absorbing component, $\mathrm{rBC}$-free particles, i.e., non-absorbing particles, cross the laser-beam unaltered and the peak amplitude of the LSD signal is proportional to the scattering cross-section of the particle. Certified polystyrene latex (PSL; refractive index $=1.59$ ) size standards are used to calibrate the scattering cross-section measurement of the LSD detector as described in Laborde et al. (2012b). The optical size of rBC-free particles is inferred from the measured scattering cross-section, using Mie theory for a homogeneous sphere and assuming a refractive index of 1.59 (see below). For the SP2 settings used here, the LSD covers a size range of the optical diameters of roughly 140-290 nm (Table 1).

Particles containing $\mathrm{rBC}$ heat up as they pass through the laser beam, thereby resulting in the evaporation of the rBC-free coatings and eventually even the rBC core. Therefore, the peak amplitude of the LSD signal does not represent the scattering cross-section of the undisturbed particles. However, Gao et al. (2007) introduced the position 

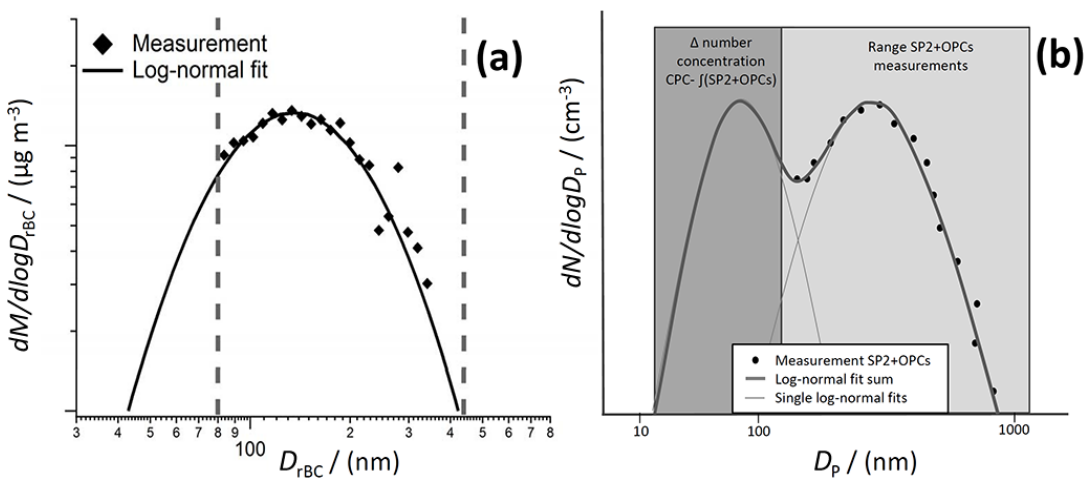

Figure 1. (a) Scheme illustrating the determination of $\mathrm{rBC}$ mass size distributions from SP2 measurements (diamonds) within the SP2 measurement range (between the grey dashed lines) and a log-normal fit (black line). Based on the fit, the total rBC mass concentration can be derived. For details see Sect. 2.2. $d M / d \log D_{\mathrm{rBC}}$ : $\mathrm{rBC}$ mass size distribution. $\mathrm{d} N / \mathrm{d} \log D_{\mathrm{p}}$ : particle number size distribution. (b) Scheme of the total particle size distributions measured: Dots represent the combined measurements of SP2 and FSSP-300 (accumulation mode; light grey box). The integral number concentration of particles smaller $0.14 \mu \mathrm{m}$ (Aitken mode; grey box) is derived from the difference of the CPC number concentration to integral number concentration of SP2 and FSSP 300 in the accumulation mode. Log-normal fits are applied to the measured size distribution and extrapolated toward smaller sizes. For details see Sect. 2.2.

sensitive detector (PSD), a modified multi-element LSD, which makes it possible to determine the scattering crosssection of rBC-free- as well as rBC-containing particles at any time (or position) in the laser beam. The approach for the time-resolved scattering cross-section analysis applied here is largely based on Gao's method, described in detail in Laborde et al. (2012a). The scattering cross-section of the unperturbed particle is obtained from the LSD signal in the leading edge of the laser beam (up to $3 \%$ of maximal laser intensity) before the onset of coating evaporation. This is commonly referred to as the leading-edge-only (LEO) fit method (Gao et al., 2007). The LEO-fit extends the upper detection limit for the optical sizing of rBC-free particles to larger diameters, in our case up to around $550 \mathrm{~nm}$ (Table 1). Similar to the standard optical sizing (see above), the optical diameter of $\mathrm{rBC}$-free particles is inferred from the scattering cross-section measured with the LEO-fit approach assuming a homogeneous sphere and a refractive index of $1.59+0.00 \mathrm{i}$ (see below). The uncertainty of the optical sizing associated with uncertainties of the assumed refractive index is about $5 \%( \pm \sim 10 \mathrm{~nm})$ for a $200 \mathrm{~nm}$ particle and about $8 \%$ $( \pm \sim 50 \mathrm{~nm}$ ) for a $600 \mathrm{~nm}$ particle when varying the refractive index from $1.59+0.00 \mathrm{i}$ to $1.50+0.00 \mathrm{i}$ or $1.70+0.00 \mathrm{i}$. Inferring the optical size of $\mathrm{rBC}$-containing particles from their scattering cross-section is not straightforward as the particles are inhomogeneous and typically not spherical. We use the approach described in Schwarz et al. (2008b) and Laborde et al. (2012b). Briefly, a concentric-spheres coreshell morphology is assumed for the Mie calculations. The core size is constrained by the $\mathrm{rBC}$ core mass equivalent diameter, $D_{\mathrm{rBC}}$, from the incandescence measurement. To obtain the total optical diameter, $D_{\text {opt }}$, of the unperturbed particle, including core and shell, the diameter of the total particle is varied until the calculated scattering cross-section matches the measured scattering cross-section. The coating thickness $\left(\Delta R_{\text {coat }}\right)$ of a $\mathrm{BC}$-containing particle is defined as the difference between the radii of the unperturbed particle and the BC core, i.e., $\Delta R_{\text {coat }}=0.5\left(D_{\mathrm{opt}}-D_{\mathrm{rBC}}\right)$. This provides information about the mixing state of individual $\mathrm{BC}$-containing particles. In this study, refractive indices of $2.26+1.26 \mathrm{i}$ and $1.59+0.00 \mathrm{i}$ are used for the $\mathrm{rBC}$ core and the coating, respectively, in the Mie calculations. The particular value for the refractive index of the $\mathrm{BC}$ core was measured by Moteki et al. (2010) for thermally denuded ambient BC particles using an APM (Aerosol Particle Mass Analyzer) and an SP2.

The reliability of the SP2 has been studied extensively by inter-comparisons of six different SP2s at the Aerosol Interaction and Dynamics in the Atmosphere (AIDA) chamber in November 2011. Laborde et al. (2012b) report a reproducibility of $10 \%$ for the rBC mass and $17 \%$ for the coating thicknesses for this inter-comparison study. However, due to calibration uncertainties the absolute uncertainty may be higher. Kondo et al. (2011b) compared rBC mass concentrations measured with the SP2 and a filter-based absorption photometer, continuous soot-monitoring system (COSMOS) and found that the methods agree to within about $10 \%$ on average. Besides, Laborde et al. (2013) made a comparison of the rBC measurements by the SP2 with a collocated elemental carbon (EC) measurement by a thermal-optical EC instrument (Sunset ECOC analyzer), revealing agreement well within the uncertainty of either method. The SP2 was prepared for the research flights, following the instructions given in Laborde et al. (2012b). For this study we estimate a total uncertainty of $15 \%$ for the rBC mass, which includes the described reproducibility and calibration uncertainties (Laborde et al., 2012b) combined with uncertainties due to airborne in situ measurements. 


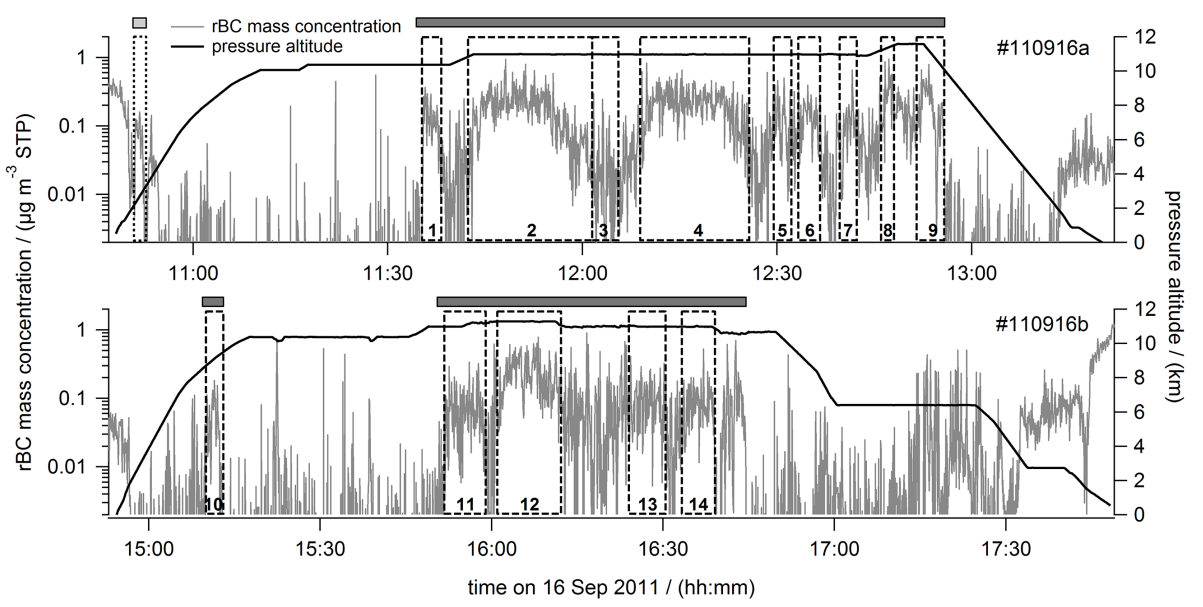

Figure 2. Time series of the rBC mass concentration (STP) in the SP2 size range (grey lines) for flight \#110916a (up) and flight \#110916b (bottom). The flight altitude is shown in black lines. The grey bars represent the sequences of continuous forest-fire aerosol layer sampling, i.e., the flight time in the area where the Pagami Creek fire aerosol layer was situated. The dashed boxes represent sequences, which are used for detailed analysis. These 14 sequences were chosen to represent parts of the aerosol layer with high and low loads, without interference of other aerosol sources such as aircraft emissions. The region between segment 12 and 13 was excluded because here the mixture of aircraft exhausts and contrails with the Pagami Creek fire plume was sampled.

The aerosol inlet system on the DLR Falcon research aircraft has been extensively tested and successfully used for years. For example, Fiebig (2001) investigated the inlet system on the Falcon and Schumann et al. (2011b) show the cutoff of the Falcon aircraft inlet and the effect on the derived particle size distribution.

To obtain particle number size distributions in the size range of $\sim 0.15-30 \mu \mathrm{m}$, measurements from the SP2 and the FSSP-300 are combined. To ensure a correct signal-todiameter assignment for the optical particle counters such as the FSSP-300 $(\lambda=633 \mathrm{~nm})$, an appropriate refractive index has to be applied for the bulk aerosol. Problems with this procedure are explained in more detail in Weinzierl et al. (2009), for example. Real parts of the refractive index at visible wavelengths of several types of organic aerosols and biomass-burning organic aerosol are reported to be between 1.50 and 1.63 and between 1.56 and 1.64, respectively (Kondo et al., 2011a, and references therein). However, the FSSP-300 cannot distinguish between BC-free and $\mathrm{BC}$-containing particles. Thus, the particles in the considered FSSP-300 size range are assumed to be non-absorbing (the imaginary part of the refractive index is zero), with real parts of the bulk refractive index ranging between 1.59 and 1.60. That increases the uncertainty of the FSSP-300 data compared to the SP2 size distribution, which distinguishes between BC-containing and BC-free particles. However, due to a low fraction of $\mathrm{BC}$-containing particles in the data set presented later (8-13\%) we expect only minor effects of the refractive index assumption on the inferred particle size distribution. The combination of the FSSP-300 and the SP2 data allows us to derive the particle number size distribution in the size range between about $0.14 \mu \mathrm{m}$ and
$30 \mu \mathrm{m}$ (Table 1). To obtain information on the size distribution in the Aitken mode $\left(D_{\text {opt }}<0.14 \mu \mathrm{m}\right)$ data from the CPC/CPSA is added. The number concentration of Aitken mode particles in the size range between $0.01 \mu \mathrm{m}$ (lower CPC cut-off) and $0.14 \mu \mathrm{m}$ (lower SP2 cut-off) is determined as the differential of particles in the accumulation mode, i.e., measured with the SP2 and the FSSP-300 and the integral number concentration determined by the CPC/CPSA. This method is only valid if nucleation mode particles can be excluded. This is ensured by the measurement of particles in the size range $10-14 \mathrm{~nm}$, showing low particle number concentrations $\left(<260 \mathrm{~cm}^{-3}\right)$. The shape of the particle number size distribution in the Aitken mode range is approximated by applying a log-normal fit, assuming that a single log-normal mode represents all particles in the Aitken mode (Weinzierl et al., 2011) with the particular minimum between Aitken and accumulation mode being operationally defined as $0.14 \mu \mathrm{m}$. Figure $1 \mathrm{~b}$ sketches the procedure for fitting the number size distributions. The parameters for a log-normal fit of mode $j$ are the mode number concentration $\left(N_{j}\right)$, the geometric standard deviation $\left(\mathrm{GSD}_{j}\right)$, and the count median diameter $\left(\mathrm{CMD}_{j}\right)$. The $\mathrm{CMD}$ for the Aitken mode, $\mathrm{CMD}_{1}$, is set constant to $0.07 \mu \mathrm{m}$, and $\mathrm{GSD}_{1}$ is estimated to provide the best fit to the residual between the measured accumulation mode and the log-normal fit to the accumulation mode in the lower end of the measurement range (of SP2/FSSP-300) and to match values regularly found for forest-fire aerosol layers (see Sect. 4.2). In addition to one log-normal distribution used to describe the size distribution in the Aitken mode, one or two log-normal distributions are applied to parameterize the particle size distribution in the accumulation mode and the coarse mode, i.e., the measured size range of the SP2 and 
FSSP-300. Because no considerable number fraction of particles was measured in the coarse mode, no separate coarse mode fit was applied.

Unless stated otherwise, the data presented in this study refer to standard temperature and pressure (STP; $273.15 \mathrm{~K}$, $1013.25 \mathrm{hPa}$ ), corresponding to mixing ratios. STP concentration data can be converted to ambient conditions by applying a factor $f_{\text {STP }}$ indicated in Table 2 .

To determine the origin and the dispersion of the investigated aerosol, we use the Hybrid Single Particle Lagrangian Integrated Trajectory Model HYSPLIT (Draxler and Hess, 1997, 1998). Input for dispersion calculations is the location of the forest fire and the altitude range of the emission. For the HYSPLIT dispersion runs the following assumptions are made: the dispersion is calculated for $0.5^{\circ}$ grid cells for $3 \mathrm{~h}$ time steps. All particles are set to a diameter of $1 \mu \mathrm{m}$ and a particle density of $1 \mathrm{~g} \mathrm{~cm}^{-3}$. The particle deposition velocity is assumed to be $0.1 \mathrm{~mm} \mathrm{~s}^{-1}$ for all particles. Wet deposition is not considered for this qualitative approach. HYSPLIT is initialized with meteorological data from the European Centre for Medium-Range Weather Forecasts (ECMWF) and the Global Forecast System (GFS). In this study only the results for the ECMWF data are presented because no relevant differences are observed for the different meteorological data sets.

\section{Results from the measurements in the Pagami Creek forest-fire plume}

On 16 September 2011, two flights were performed with the DLR Falcon. For the first flight (\#110916a, 10:48-13:20 UTC), the Falcon flew from Oberpfaffenhofen (EDMO; $48^{\circ} 05^{\prime} \mathrm{N}, 11^{\circ} 16^{\prime} \mathrm{E}, 593 \mathrm{~m}$ a.s.l.) to Neubrandenburg-Trollenhagen (ETNU; 53 $36^{\prime} \mathrm{N}, 13^{\circ} 18^{\prime} \mathrm{E}$, 69 m a.s.1.), both in Germany. The second flight (\#110916b, 14:54-17:48 UTC) was from Neubrandenburg-Trollenhagen back to Oberpfaffenhofen. The scope of these two flights was to sample contrails from commercial aircraft. To achieve this, the aircraft climbed to more than $10 \mathrm{~km}$ altitude and stayed between $10.0 \mathrm{~km}$ and $11.8 \mathrm{~km}$ for roughly $105 \mathrm{~min}$ and 95 min during flights \#110916a and \#110916b, respectively. Figure 2 shows the time series of rBC mass concentration for both flights with elevated $\mathrm{rBC}$ mass concentrations at high altitudes (>10 km a.s.l.) starting at about 11:45 UTC. Averaged 10 s rBC mass concentrations were observed as high as $0.67 \mu \mathrm{g} \mathrm{m}^{-3}$ (STP). For comparison, maximum $\mathrm{rBC}$ mass concentrations in the polluted boundary layer over Munich, averaged for $10 \mathrm{~s}$, showed similar values with roughly $0.70 \mu \mathrm{g} \mathrm{m}^{-3}$ (STP) on that day. The observed aerosol layer was visible by eye as distinct broad greyishbrownish aerosol layer (Fig. 3) and covered a large area over northeastern Germany. Figure 4 gives an overview of the horizontal distribution of the aerosol layer during the two flights on 16 September 2011 by means of color-coded rBC

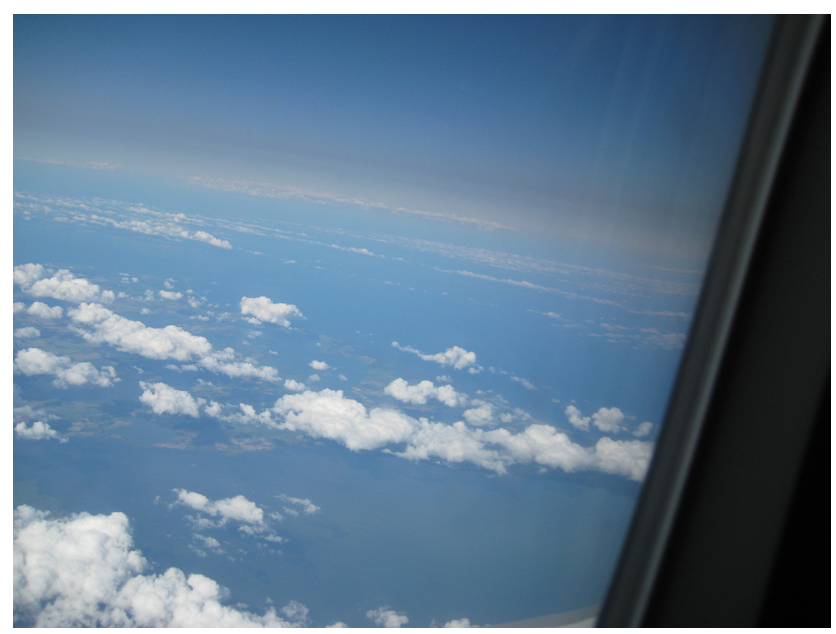

Figure 3. Photograph of the Pagami Creek fire plume taken from DLR Falcon research aircraft over Germany (16 September 2011, 12:11 UTC; $11.1 \mathrm{~km}$ a.s.1.).

mass concentrations (size range: $80-440 \mathrm{~nm}$ ) along the flight track. To emphasize upper tropospheric BC, we show only values for $\mathrm{rBC}$ mass concentrations above $9 \mathrm{~km}$ a.s.l. In the following we explicitly investigate the chemical, microphysical and optical properties of this vast aerosol layer and we will show that this layer originated from the Pagami Creek fire in North America. In this study we therefore refer to the aerosol layer observed over Germany on 16 September 2011 as Pagami Creek fire aerosol layer or Pagami Creek fire plume. We are aware that the observed layer does not contain the entire emissions of the Pagami Creek fire and smaller layers and plumes might have been transported along other trajectories at other altitudes, which we did not observe and which are consequently not presented in this study.

\subsection{Microphysical properties of the observed aerosol layer}

To derive particle number size distributions and $\mathrm{BC}$ mass distributions and to infer BC particle mixing state, we subdivide the measurements in the Pagami Creek fire aerosol layer into sequences with rather homogeneous $\mathrm{rBC}$ mass concentrations. Altogether, 14 time sequences are chosen, as shown in Fig. 2, including sequences with maximum concentrations as well as less concentrated sequences within this heterogeneous aerosol layer. Aircraft exhaust and contrail sequences, which are characterized by short and distinct increases of particle and trace gas concentrations, are excluded, using $\mathrm{NO}_{\mathrm{y}}$ and $\mathrm{SO}_{2}$ as aircraft plume markers.

\subsection{1 rBC mass size distributions}

Figure 5 shows the median measured $\mathrm{rBC}$ mass size distribution and log-normal fits for the measured $\mathrm{rBC}$ mass size distributions of the Pagami Creek fire plume of all described 
Table 2. rBC characteristics and characteristics of the total particle number size distributions in the Pagami Creek fire plume. Shown are the minimum, median, and maximum values of $\mathrm{rBC}$ mass concentrations, the parameters of the log-normal fit to the rBC mass size distribution, the parameters of the log-normal fit to the total number size distribution, and STP-ambient conversion factors of 14 sequences during the forest-fire aerosol layer measurements. Values in italics are extrapolated from total number concentration values. In comparison to the rBC mass concentration in the Pagami Creek fire within the SP2 size range $\left(0.03-0.29 \mu \mathrm{g} \mathrm{m}^{-3}\right)$ the free tropospheric background sequence has a mean $\mathrm{rBC}$ mass concentration of $<0.004 \mu \mathrm{g} \mathrm{m}^{-3}$. GSD is the geometric standard deviation and $\mathrm{CMD}$, the count median diameter.

\begin{tabular}{|c|c|c|c|c|}
\hline \multirow[b]{2}{*}{ Parameter } & & \multicolumn{3}{|c|}{$\begin{array}{l}\text { Sequence with } \mathrm{rBC} \\
\text { mass concentration }\end{array}$} \\
\hline & & minimum & median & maximum \\
\hline \multicolumn{5}{|c|}{ rBC mass concentration (in SP2 size range) (STP) } \\
\hline & $\left(\mu \mathrm{g} \mathrm{m}^{-3}\right)$ & 0.03 & 0.12 & 0.29 \\
\hline \multicolumn{5}{|c|}{$\begin{array}{l}\text { Parameters of log-normal fit to rBC mass size } \\
\text { distribution as function of } D_{\mathrm{rBC}} \text { (STP) }\end{array}$} \\
\hline rBC total mass concentration & $\left(\mu \mathrm{g} \mathrm{m}^{-3}\right)$ & 0.03 & 0.16 & 0.35 \\
\hline GSD & - & 1.75 & 1.70 & 1.70 \\
\hline CMD & $\mathrm{nm}$ & 121 & 144 & 150 \\
\hline \multicolumn{5}{|c|}{$\begin{array}{l}\text { Parameters of log-normal fit to total particle number } \\
\text { size distribution as a function of } D_{\text {opt }} \text { (STP) }\end{array}$} \\
\hline$N_{1}$ & $\mathrm{~cm}^{-3}$ & 1077 & 1517 & 760 \\
\hline $\mathrm{GSD}_{1}$ & - & 1.36 & 1.30 & 1.30 \\
\hline $\mathrm{CMD}_{1}$ & $\mathrm{~nm}$ & 70 & 70 & 70 \\
\hline$N_{2}$ & $\mathrm{~cm}^{-3}$ & 130 & 641 & 957 \\
\hline $\mathrm{GSD}_{2}$ & - & 1.46 & 1.41 & 1.44 \\
\hline $\mathrm{CMD}_{2}$ & $\mathrm{~nm}$ & 243 & 251 & 281 \\
\hline$N_{3}$ & $\mathrm{~cm}^{-3}$ & 1 & - & - \\
\hline $\mathrm{GSD}_{3}$ & - & 1.10 & - & - \\
\hline $\mathrm{CMD}_{3}$ & $\mathrm{~nm}$ & 550 & - & - \\
\hline STP factor & - & 3.92 & 3.93 & 4.15 \\
\hline
\end{tabular}

sequences. Error bars represent $15 \%$ uncertainty. The total rBC mass concentration was estimated with adding the extrapolated tails (log-normal fit to the measurements) of the $\mathrm{rBC}$ mass size distribution to the $\mathrm{rBC}$ measurement of the SP2 integrated over the whole detection range (see Sect. 2.2 for details). The tails of the size distribution consistently contributed $\sim 20 \%$ to the total estimated $\mathrm{rBC}$ mass for each of the 14 plume sequences. Due to a higher fraction of fresh and small rBC-particles and possibly even an extra mode of small rBC particles not captured by the log-normal fitting, the determined $\mathrm{rBC}$ mass fraction might be lower in the boundary layer, implying a potential systematic uncertainty for the comparison of the determined total $\mathrm{rBC}$ mass of the Pagami Creek fire plume and the boundary layer. However, with increasing age the mode of small rBC particles shifts to larger sizes, therefore we expect the log-normal fit to capture the total mass fairly well. The mass median diameter (MMD), which is equal to the modal diameter for a log-normal size distribution, of all mass size distributions of the Pagami Creek fire plume is in the size range of 120 to $160 \mathrm{~nm}$. The total $\mathrm{rBC}$ mass concentrations for the $14 \mathrm{se}-$ quences $\left(0.03-0.35 \mu \mathrm{g} \mathrm{m} \mathrm{m}^{3}\right.$; STP) reveal a variability factor of approximately 10. A UTLS background sequence at the same altitude as the Pagami Creek fire plume shows rBC average total mass concentrations $<0.01 \mu \mathrm{g} \mathrm{m}^{-3}$ (STP), implying the Pagami Creek fire plume contains a factor of 3-34 higher rBC mass concentrations than the background air. Parameters of the log-normal fit to the $\mathrm{rBC}$ mass size distribution (STP) and the total rBC mass concentrations derived from the log-normal fit (STP) are shown in Table 2.

\subsubsection{Total particle number size distributions}

Figure 6 shows the total particle number size distributions of the Pagami Creek fire plume in comparison with the UTLS background aerosol sequence. The presented minimum, median, and maximum size distributions represent the range of observations for the 14 considered sequences (Fig. 2) in the Pagami Creek fire plume. The parameters of the fitted total number size distributions (Fig. 6) are shown in Table 2. Additionally, the factors used to convert the data from STP to ambient conditions are given in Table 2. For the Aitken mode $(j=1)$, i.e., particles $<0.14 \mu \mathrm{m}$ (Table 2 ), the number 

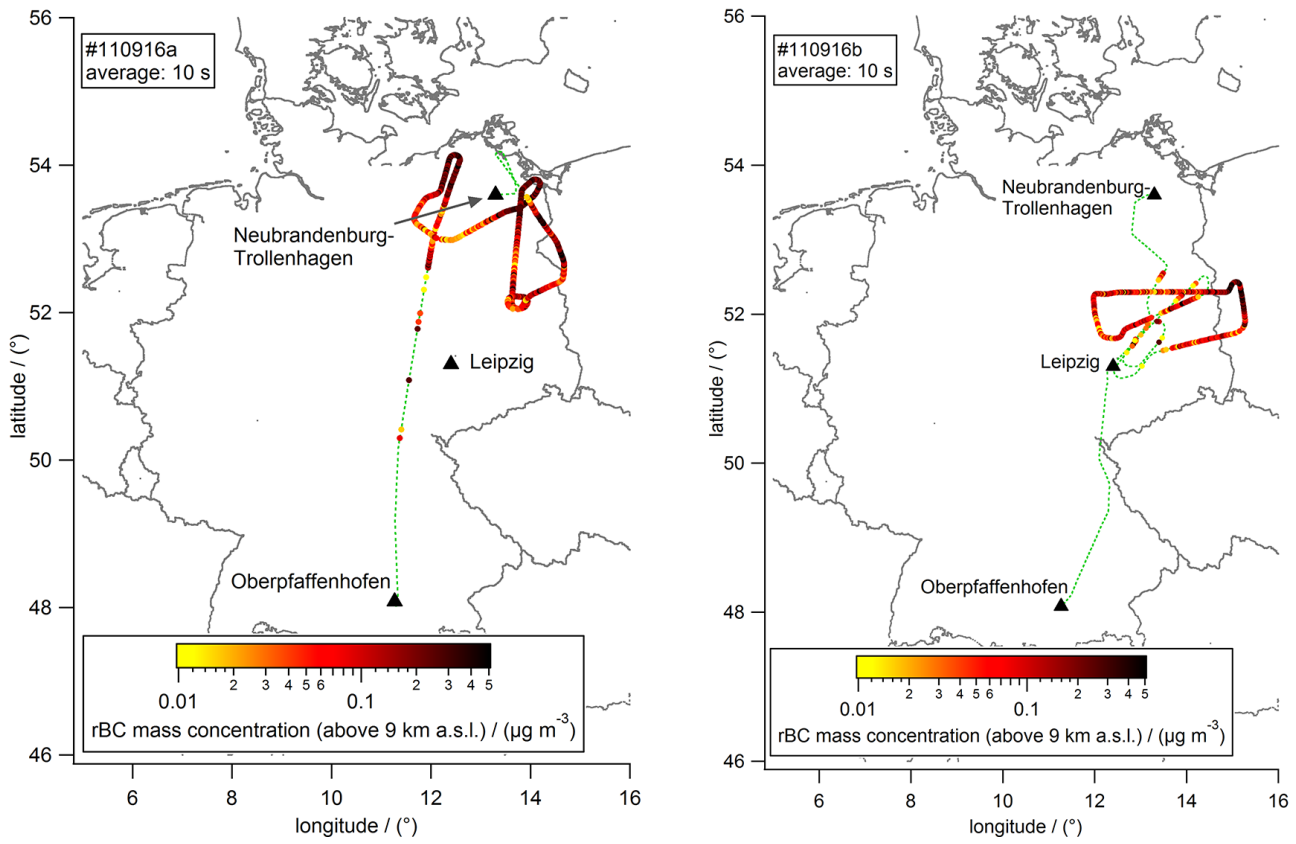

Figure 4. Flight tracks for flight \#110916a (left) and \#110916b (right) on 16 September 2011 with averaged (10 s) rBC mass concentrations (STP) color-coded along the flight track. For clarity, only data for altitudes above $9 \mathrm{~km}$ a.s.l. and $\mathrm{rBC}_{\text {mass concentrations }>0.01 \mu \mathrm{g} \mathrm{m}}{ }^{-3}$ are shown.

concentration $\left(N_{1}\right)$ is directly inferred from the measurements (see Sect. 2.2), while $\mathrm{CMD}_{1}$ has to be assumed and $\mathrm{GSD}_{1}$ is iteratively approximated. The minimum and the maximum values of $N_{1}$ for all 14 sequences are $760 \mathrm{~cm}^{-3}$ and $2228 \mathrm{~cm}^{-3}$, respectively. The total number concentrations in the measured size range (accumulation mode) vary roughly by a factor of 7 within the 14 sequences as an indication of a heterogeneous distribution within the vertical column. In the accumulation mode the total number concentrations are factors of 14-100 times higher compared to the UTLS background sequence.

\subsubsection{Coating thickness}

Besides the size distribution information of aerosol layers, the mixing state of individual particles plays an important role in atmospheric processes. As described in Sect. 2.2, the coating thickness of individual particles inferred from the SP2 measurements delivers information about the mixing state of individual particles. Figure 7a shows normalized histograms of the observed coating thickness of all $\mathrm{BC}$-containing particles with $\mathrm{BC}$ cores in two size ranges $\left(D_{\mathrm{rBC}}=140-160 \mathrm{~nm}, D_{\mathrm{rBC}}=180-220 \mathrm{~nm}\right)$ for the 14 different sequences in the Pagami Creek fire plume. These two size ranges are chosen as examples to test if the coating thickness $\left(\Delta R_{\text {coat }}\right)$ varies with changing $\mathrm{BC}$ core size. The coating thickness of individual aerosol particles from the Pagami Creek fire aerosol layer ranges from $\Delta R_{\text {coat }}=20 \mathrm{~nm}$ up to the upper detection limit of $\sim 180 \mathrm{~nm}$, in both $\mathrm{BC}$ core size ranges shown, with a flat maximum between $\sim 80 \mathrm{~nm}$ and $160 \mathrm{~nm}$ (saturated signals originating from particles with coatings thicker than $180 \mathrm{~nm}$ were also frequently observed). The small number of BC cores with coatings below $20 \mathrm{~nm}$ observed within the Pagami Creek fire plume is likely from UTLS background particles and/or aircraft emissions. The observed coating thickness distributions are very similar for all 14 sequences, indicating very homogeneous BC particle properties across the different plume areas.

For comparison, the $\mathrm{BC}$ particles observed in the boundary layer in the regions of Neubrandenburg and Munich are thinly coated and show median coating thicknesses of $<20 \mathrm{~nm}$ with the majority $(75 \%)$ showing coating thicknesses of $<65 \mathrm{~nm}$. Thus the particles in the observed Pagami Creek fire aerosol layer exhibit much larger coating thicknesses than younger aerosol particle populations such as the planetary boundary layer (PBL) aerosol. The negative coating thickness values measured for some particles (Fig. 7a) are caused by random noise and potential systematic biases resulting from the assumptions made about the refractive indices and particle shape. The systematic uncertainty for the coating thickness is assessed to be $< \pm 20 \mathrm{~nm}$.

The raster graphic in Fig. 7b illustrates the relationship between the $\mathrm{BC}$ core size and the coating thickness integrated over all Pagami Creek fire plume sequences. The color-coding and the black line represent the number of particles in each pixel and the median coating thickness, respectively. The grey lines represent the detection limits of this method (see figure caption for explanation). Coating 


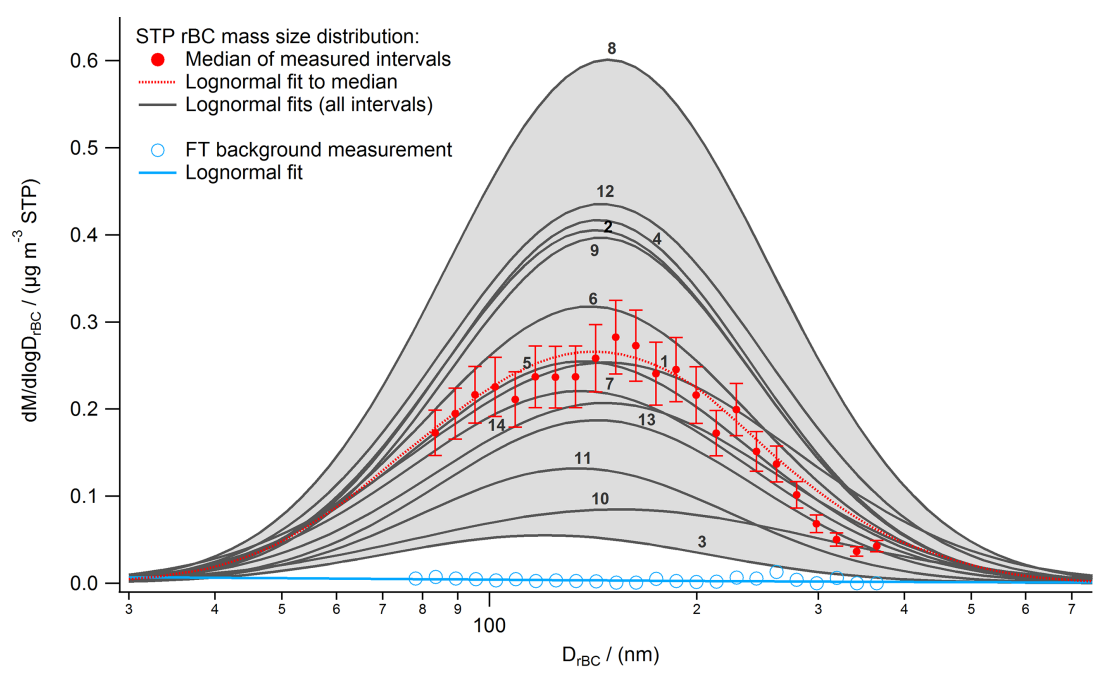

Figure 5. Median rBC mass size distribution (red dots) out of the 14 measurement sequences (see Fig. 2) in the Pagami Creek fire plume. Log-normal fits (solid lines) are shown for all sequences for the measured size range of $80-250 \mathrm{~nm}$. The grey shaded area represents the range between maximum and minimum log-normal fit. The mean total $\mathrm{rBC}$ mass concentration (accounting for the data outside the SP2 range) is $0.03-0.35 \mathrm{\mu g} \mathrm{m}^{-3}$ (STP) for the 14 sequences in the forest-fire layer, indicated by the numbering. Error bars represent $15 \%$ uncertainty (see Sect. 2.2). For comparison the rBC mass of a free tropospheric (FT) background sequence (blue) is shown.

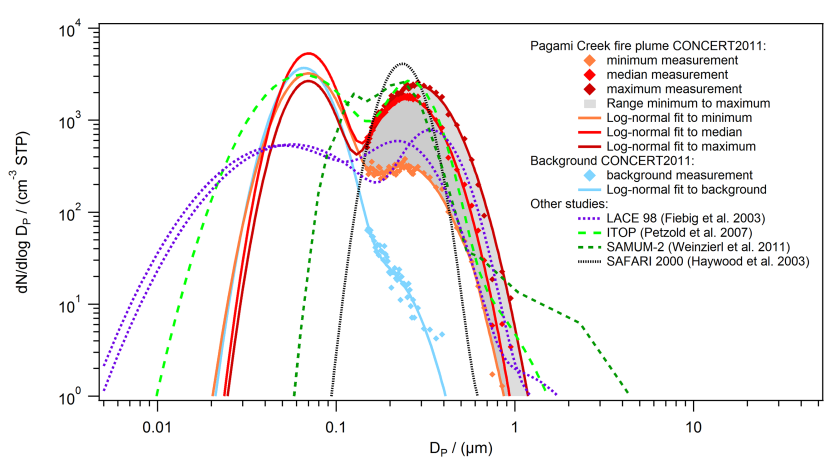

Figure 6. Number size distributions (STP) for background aerosol (blue markers), minimum (orange markers), median (red markers), maximum (dark red markers), and range (light grey area) of measurements in the Pagami Creek fire plume. Number size distributions are extrapolated by log-normal fits for the minimum, median, maximum, and background measurements (orange, red, dark red, and blue solid lines), and compared to forest-fire plumes (dashed lines) from LACE 98 (purple) as ambient values, ICARTT ITOP (International Consortium for Atmospheric Research on Transport and Transformation, Intercontinental Transport of Pollution; light green), SAMUM-2 (Saharan Mineral Dust Experiment; dark green), and SAFARI 2000 (Southern African Regional Science Initiative; black). Normalized values from SAFARI 2000, showing only the accumulation mode due to a lack of measurements for particle sizes $<100 \mathrm{~nm}$, are scaled to similar magnitudes.

thickness values up to the detection limit, which are as high as $\Delta R_{\text {coat }} \approx 240 \mathrm{~nm}$ for core sizes $D_{\mathrm{rBC}} \leq 100 \mathrm{~nm}$, are observed for all core sizes. The distribution of coating thickness values is similarly broad for all BC core sizes, but particles with thin coatings $\left(\Delta R_{\text {coat }} \leq 40 \mathrm{~nm}\right)$ are always a negligible fraction. The median coating thickness is $\Delta R_{\text {coat }} \approx 105-$ $136 \mathrm{~nm}$ for the 14 flight sequences independent of $\mathrm{BC}$ core size (note, the median coating thickness values for $\mathrm{BC}$ core sizes $D_{\mathrm{rBC}}<90 \mathrm{~nm}$ and $>170 \mathrm{~nm}$ are likely biased by detection limit effects). This translates to median shell / core diameter ratios of $D_{\mathrm{opt}} / D_{\mathrm{rBC}}=3.7,2.8$ and 2.4 at $D_{\mathrm{rBC}}=90 \mathrm{~nm}$, $130 \mathrm{~nm}$ and $170 \mathrm{~nm}$, respectively, while the highest observed values are as high as $D_{\mathrm{opt}} / D_{\mathrm{rBC}}=7.4$ at $D_{\mathrm{rBC}} 80 \mathrm{~nm}$.

\subsection{Estimates on the dimension and classification of the observed aerosol layer}

Figure 8 shows vertical profiles of $\mathrm{rBC}$ mass concentration for both flights on 16 September 2011 with $100 \mathrm{~m}$ vertical resolution, including the median and $10 \mathrm{th} / 25 \mathrm{th} / 75 \mathrm{th} / 90 \mathrm{th}$ percentiles for the specific size range $80-440 \mathrm{~nm}$. The vertical profiles are averaged over the entire flight for altitudes $>2 \mathrm{~km}$. For altitudes $<2 \mathrm{~km}$ the profiles are separately shown for the PBL over Oberpfaffenhofen and NeubrandenburgTrollenhagen. A prominent feature in both vertical profiles is the presence of increased aerosol concentrations at altitudes above $10 \mathrm{~km}$ a.s.l., attributable to the Pagami Creek fire plume. According to Fig. 8, the Falcon did not reach the top of the plume. However, in addition to the Falcon, the groundbased lidar in Leipzig also observed the Pagami Creek fire aerosol layer on 16 September 2011 in the UTLS. Figure 9 presents lidar observations performed in Leipzig, Germany $\left(51.3^{\circ} \mathrm{N}, 12.4^{\circ} \mathrm{E}\right)$, between 08:36 UTC and 10:30 UTC on 16 September 2011. In the time series of the $532 \mathrm{~nm}$ rangecorrected backscatter signal (Fig. 9a), the Pagami Creek fire plume was observed at altitudes between $8 \mathrm{~km}$ and 

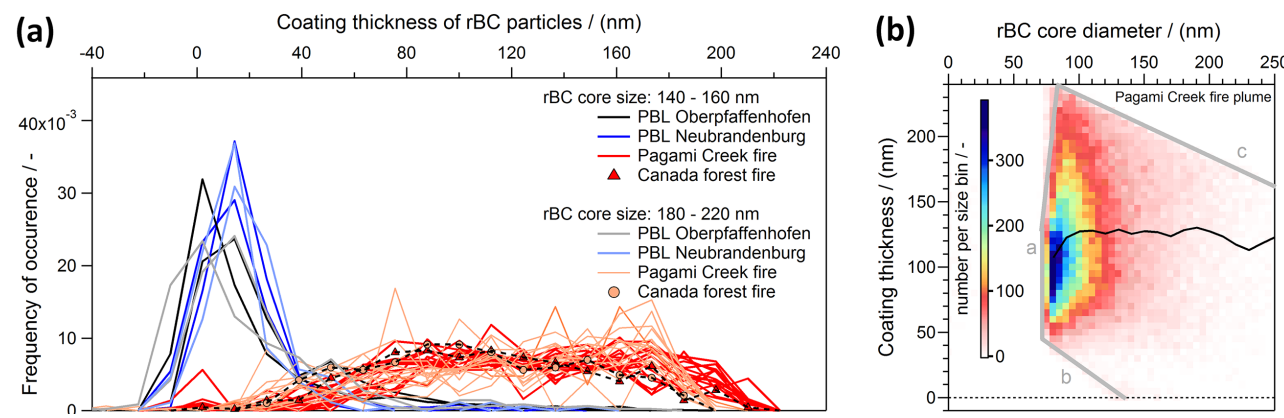

Figure 7. (a) Histograms of the coating thickness for 14 sequences (see Fig. 2) inside the Pagami Creek fire aerosol layer (red) and for fresh boundary layer aerosols in Oberpfaffenhofen, near Munich, and Neubrandenburg in black and blue, respectively, for rBC cores sizes of 140-160 nm (intense color) and 180-220 nm (light color). (b) The relationship between rBC core diameter and coating thickness for all 14 sequences in the forest-fire aerosol layer is shown as color-coded 2-D histogram including the median coating thickness (black line). The methodological boundaries are indicated by grey lines (a: rBC core below BID lower detection limit; b: scattering signal below LSD lower detection limit; c: scattering signal above LSD higher detection limit).

$12 \mathrm{~km}$ a.s.l. A humid layer was present below $1.5 \mathrm{~km}$ altitude, which causes the vertically striped pattern in the signal of the forest-fire plume in the UTLS due to partial attenuation of the laser light by thin clouds or haze. The base of the heterogeneously-layered Pagami Creek fire plume slowly descended with time. In the course of the late morning around 10:30 UTC the layer diminished above Leipzig. The timeresolved lidar profiles strongly confirm our observations, showing the maximum of the plume between $10.0 \mathrm{~km}$ and $11.5 \mathrm{~km}$ a.s.l. and an upper limit at roughly $12 \mathrm{~km}$. At the time of the Falcon flyover (15:43 UTC) in Leipzig, neither the DLR Falcon nor the lidar observed signatures of the plume. In agreement with the lidar and in situ observations, the spaceborne lidar CALIPSO (not shown ${ }^{2}$ ) observed the Pagami Creek fire plume on 16 September 2011 at about 10$12 \mathrm{~km}$ altitude over Europe.

The vertical profiles of particle backscatter coefficient $\beta_{\text {par }}$ and particle linear depolarization ratio $\delta_{\text {par }}$ are presented in Fig. $9 \mathrm{~b}$ based on the averaged $532 \mathrm{~nm}$ elastic backscatter signal of the time period from 08:36-09:25 UTC. Sequences strongly affected by the low-level clouds are removed from the analysis to increase the signal-to-noise ratio. Because no Raman-scattering information is available, the lidar data analysis is performed using the Klett-Fernald method (Klett, 1981; Fernald, 1984). This requires the assumption of the extinction-to-backscatter ratio (lidar ratio). Because earlier studies (Tesche et al., 2011; Groß et al., 2013) show that a lidar ratio of $70 \mathrm{sr}$ is reasonable for biomass-burning aerosol, we use this value for the analysis of the lidar data. Uncertainties in the retrieved optical properties are due to noise and the assumption of the lidar ratio (Rocadenbosch et al., 2010). Particle linear depolarization ratios of around 6-8\% at $532 \mathrm{~nm}$ are observed throughout the Pagami Creek fire

\footnotetext{
${ }^{2}$ See http://www-calipso.larc.nasa.gov/products/lidar/browse_ images/show_date.php?s=production $\& \mathrm{v}=\mathrm{V} 3-01 \&$ browse_date $=$ 2011-09-16.
}

plume between $8 \mathrm{~km}$ and $12 \mathrm{~km}$ altitude. This is comparable to findings by Groß et al. (2013) who presented particle linear depolarization ratios of $7 \pm 2 \%$ for aged (4-6 day-old) biomass-burning aerosol from their own measurements and summarize that values between $2 \%$ and $8 \%$ are reported in the literature for fresh to aged pure biomass-burning aerosol. Müller et al. (2007) report that particle linear depolarization ratios $<5 \%$ can be expected for biomass-burning aerosol particles, probably due to their spherical shape. However, in agreement with our results, Müller et al. (2007) observed particle linear depolarization ratios of up to $10 \%$ at $532 \mathrm{~nm}$ wavelength during the Lindenberg Aerosol Characterization Experiment 1998 (LACE 98), which they explained by soil dust particles possibly lifted together with the smoke particles at the source of the fire. Weinzierl et al. (2011) report particle linear depolarization ratios of $6-16 \%$ (median: $13 \%)$ at $532 \mathrm{~nm}$ wavelength for biomass-burning aerosol mixed with mineral dust from the Sahara measured during the SAMUM-2 field experiment in the Cape Verde region. Other aerosol types can be excluded as source of the observed layer with ice clouds and mineral dust having higher and sea salt and sulphates having lower particle linear depolarization ratios (Groß et al., 2013). A mixture of ash and sulphate of volcanic origin could also explain the observed depolarization ratios besides biomass-burning aerosol. However, volcanic eruptions did not occur in an appropriate spatiotemporal window. In addition, enhanced BC is normally not observed in volcanic ash layers (Weinzierl et al., 2012). The lidar in Leipzig only probed the edges of the plume (Fig. 4), such that the observed particle backscatter coefficient $\beta_{\text {par }}$ (up to $1 \mathrm{Mm}^{-1} \mathrm{sr}^{-1}$ ) above Leipzig is most likely lower than that found in the central part of the Pagami Creek fire aerosol layer. Using the observed particle backscatter coefficient, the optical thickness (532 nm) of the Pagami Creek fire plume is estimated to be at least $0.15-0.20$, which is in 

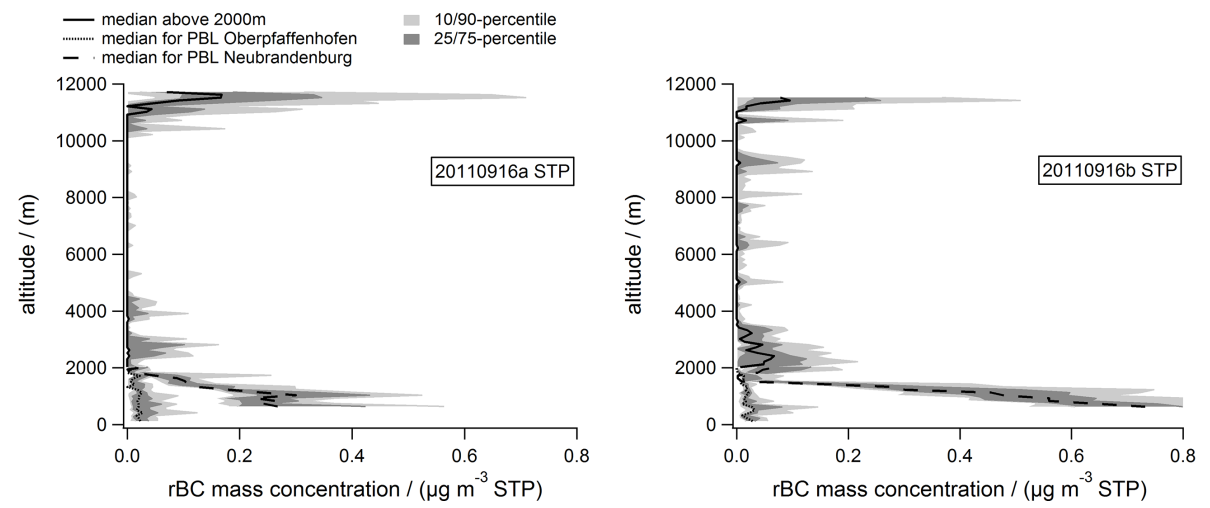

Figure 8. Vertical profiles (STP) of flight \#110916a (left) and \#110916b (right) on 16 September 2011 for rBC mass concentration measured with the SP2 as median (black lines), 25th/75th percentile (dark grey shading), and 10th/90th percentile (light grey shading) for $100 \mathrm{~m}$ vertical intervals. Below $2000 \mathrm{~m}$ the data set is split into the PBL of Oberpfaffenhofen (593 m a.s.1.; dashed line) and Neubrandenburg (69 m a.s.1.; dotted line). Values are representative for the approximate size range of $80-440 \mathrm{~nm}$ for the $\mathrm{rBC}$ particles.

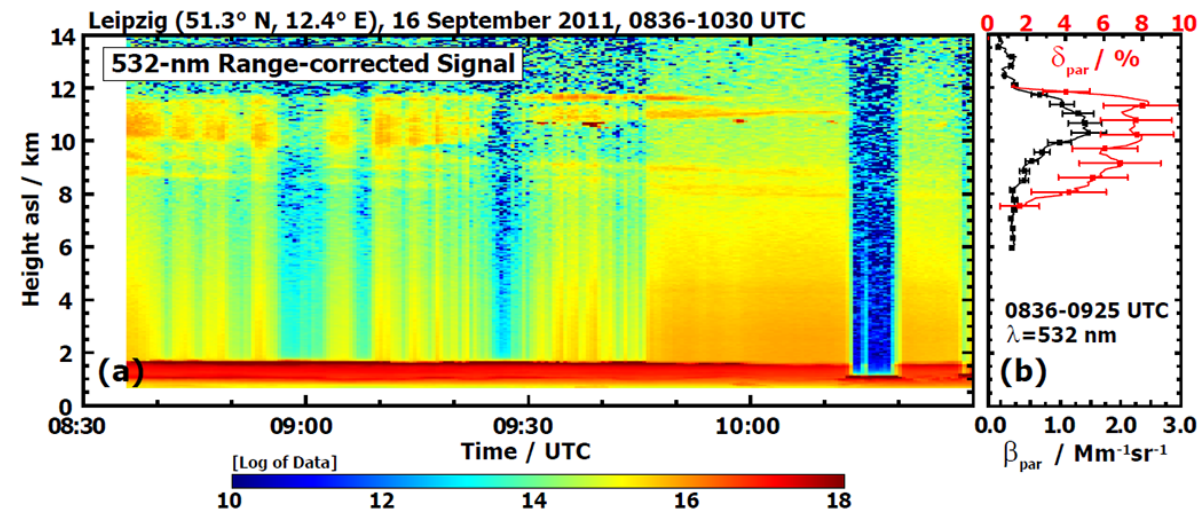

Figure 9. (a) Time-height cross-section of the $532 \mathrm{~nm}$ range-corrected backscatter signal of the lidar system in Leipzig and (b) vertical

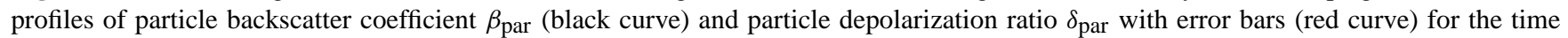
interval 08:36-09:25 UTC. The optical thickness (at $532 \mathrm{~nm}$ ) of the observed aerosol layer is derived to be 0.15-0.20.

the range of previous findings for biomass-burning aerosol layers, but higher than the median, of Weinzierl et al. (2011).

\subsection{Identification of the Pagami Creek forest fire as the source of the observed aerosol layer}

Figure 10a shows a true-color image of the Pagami Creek fire located in Minnesota, USA (approximate location $47^{\circ} 52^{\prime} \mathrm{N}$, $91^{\circ} 30^{\prime} \mathrm{W}$; US Forest Service), taken by the Moderate Resolution Imaging Spectroradiometer (MODIS) on 12 September 2011 at 18:50 UTC. This fire was caused by lightning on 18 August 2011. Before 12 September the fire did not evolve significantly and thus caused only minor pollution according to the MODIS images. On 12 September 2011 the fire grew rapidly exhibiting a thick plume, which is transported eastwards (Fig. 10a). The Pagami Creek fire burned a total area of roughly $375 \mathrm{~km}^{2}$. A cloud-top $11.0 \mu \mathrm{m}$ brightness temperature of roughly $-60^{\circ} \mathrm{C}$, corresponding to altitudes $>11 \mathrm{~km}$, was observed with MODIS, which is com- parable to deep thunderstorm clouds and is indeed colder than at any level up to $16 \mathrm{~km}$ in the radiosonde observation (RAOB) at International Falls, Minnesota, that day. Thus, this brightness temperature minimum certainly indicates cloud top altitudes up to the cold point above $12 \mathrm{~km}$ altitude. Radar echo tops on the cloud anvil reach $\sim 13.6 \mathrm{~km}$ at 19:54 UTC caused by pyro-convection forming this pyrocumulonimbus (pyroCb) cloud as a result of the extensive forest fire (Fromm et al., 2010). Similar observations of brightness temperatures for pyro-convective clouds are discussed in Damoah et al. (2006). Additional pyro-convection events are observed and described in Andreae et al. (2004) and Fromm et al. (2005). MODIS imagery suggests that the bulk emission and the pyro-convection event were limited from roughly 17:00 UTC on 12 September to 04:15 UTC on 13 September. In fact, Advanced Very High Resolution Radiometer (AVHRR) imagery (not shown) suggests that pyro-convective lofting shut down at sometime between 20:41 UTC and 22:41 UTC on 12 September. 
To show that the aerosol plumes observed by the Falcon over Germany on 16 September originated from the Pagami Creek fire, we conduct HYSPLIT dispersion calculations starting at the location of the Pagami Creek fire. Based on the described observations, we assume that the Pagami Creek fire released emissions for $12 \mathrm{~h}$ between 17:00 UTC on 12 September 2011 and 05:00 UTC on 13 September 2011 as a maximum estimate. The release location is retrieved from satellite images and the release altitude is set from ground to $11 \mathrm{~km}$ a.g.l., assuming pyro-convention (e.g., Fromm et al., 2005; Damoah et al., 2006) and a homogeneous vertical distribution. Results are presented in Fig. 10b$\mathrm{f}$, which show the column-integrated (6-14 km a.s.l.) particle number concentration (arbitrary units; a.u.) in the time from 20:00-23:00 UTC between 12 September and 16 September 2011. The calculations underline that the Pagami Creek fire plume was transported through the area and at the altitude where the aerosol layer has been measured by the Falcon and the lidar in Leipzig. According to those simulations the Pagami Creek fire plume should have reached Germany on 15 September 2011 (Fig. 10e). A detailed analysis of the simulation results suggests that the smoke layer was north of Leipzig on 15 September, explaining why the lidar in Leipzig did not detect the Pagami Creek fire plume on that day. Figure $10 \mathrm{~g}-\mathrm{h}$ show zoomed-in dispersion calculations of column-integrated (10-12 km a.s.1.) particle number concentrations on 16 September 2011 for central Europe for the time between 08:00-11:00 UTC (g), 11:00-14:00 UTC (h) and 14:00-17:00 UTC (i). Figure 10h and i additionally include the Falcon flight tracks of flight \#110916a (10:48-13:20 UTC) and \#110916b (14:54-17:48 UTC), respectively. Comparing the location of the measured plume and the plume location simulated by the dispersion calculations strongly suggest that the Pagami Creek fire is most likely the source of the observed aerosol layer. This is also supported by observations of $\mathrm{CO}$, a tracer for biomass burning, by the Infrared Atmospheric Sounding Interferometer (IASI) and by data of the GOME-2 Absorbing Aerosol Index (not shown; http://www.temis.nl) (de Graaf et al., 2005), both showing the same transportation pattern of the plume as the dispersion calculations. According to the simulations shown in Fig. $10 \mathrm{~g}-\mathrm{i}$, it seems that the measurements with the Falcon aircraft captured the tail of the plume when the maximum had already passed Germany, although for the plume position an uncertainty of 5-20\% must be assumed. This uncertainty is also in agreement with the lidar measurements, which show that the Pagami Creek fire aerosol layer was observed until 10:30 UTC (Fig. 9), while the dispersion calculations suggest that in the time from 08:00-11:00 UTC the aerosol layer had already passed Leipzig (Fig. 10g).

\section{Discussion}

\subsection{Comparison of the measurements in the Pagami Creek fire plume with other measurements during CONCERT 2011}

Although the localization and observation of elevated aerosol layers was not a scientific objective of the CONCERT 2011 field experiment, in 9 of the 11 flights elevated aerosol layers, including the Pagami Creek fire plume, were observed. From about $32.3 \mathrm{~h}$ total flight time we flew by chance roughly $3.2 \mathrm{~h}$ ( $\sim 10 \%$ of the flight time) within elevated aerosol layers (volcanic ash layers, which we intentionally measured, are not counted here). Table 3 gives an overview of all CONCERT 2011 flights, including the altitude of the detected aerosol layers. As can be seen from Table 3, most of the aerosol layers were found between $2 \mathrm{~km}$ and $5 \mathrm{~km}$ altitude with $\mathrm{rBC}$ mass concentrations of $2-425 \mathrm{ng} \mathrm{m}^{-3}$ (size range: $\left.80<D_{\mathrm{rBC}}<440 \mathrm{~nm}\right)$. Figure 11 shows the median vertical profile of the $\mathrm{rBC}$ mass concentration and the $\mathrm{rBC}$ mass mixing ratio for the entire CONCERT 2011 field experiment, i.e., for all 11 research flights, with a $500 \mathrm{~m}$ vertical resolution and a temporal resolution of $10 \mathrm{~s}$. This temporal resolution is used with consideration of the trade-off between reducing the noise from insufficient integration time and retaining sufficient horizontal resolution of about $2 \mathrm{~km}$. The $\mathrm{rBC}$ mass mixing ratio (MMR) is calculated from the mass concentration $m$ at standard conditions and the density of dry air at standard conditions $\left(\rho_{0}=1.29 \mathrm{~kg} \mathrm{~m}^{-3}\right)$ : MMR $\left[\mathrm{ng} \mathrm{kg}^{-1}\right]=m_{\mathrm{STP}}\left[\mathrm{ng} \mathrm{m}^{-3}\right] / \rho_{0}\left[\mathrm{~kg} \mathrm{~m}^{-3}\right]$. The median vertical distribution can be used as an approximation of the typical vertical profile of BC above central Europe during autumn 2011. Below roughly $2 \mathrm{~km}$ altitude the vertical profile is dominated by the influence of the boundary layer: we see the highest MMR, a small spread between 10th/90th percentiles and a decreasing $\mathrm{rBC}$ MMR with increasing altitude. Above $2 \mathrm{~km}$ the signal is dominated by the wide spread of the percentile values, showing high variability in $\mathrm{rBC}$ mixing ratios above the boundary layer. This variability can be attributed to the presence of aerosol layers as a source of heterogeneous aerosol loadings in the free troposphere. The highest variability is found above $10 \mathrm{~km}$ altitude (Figs. 8 and 11). The greatly increased 75 th and 90th percentile values at this altitude are related to the high loadings detected in the Pagami Creek fire plume.

\subsection{Comparison with previous studies from literature}

\subsection{1 rBC mass concentrations and $\mathrm{rBC}$ size distributions}

In Sect. 3 we showed that the Pagami Creek fire plume, observed in the altitude range of $9-12 \mathrm{~km}$ on 16 September 2011, reached $\mathrm{rBC}$ mass concentrations between $0.03 \mu \mathrm{g} \mathrm{m}^{-3}$ and $0.35 \mu \mathrm{g} \mathrm{m}^{-3}$ (STP), which are 

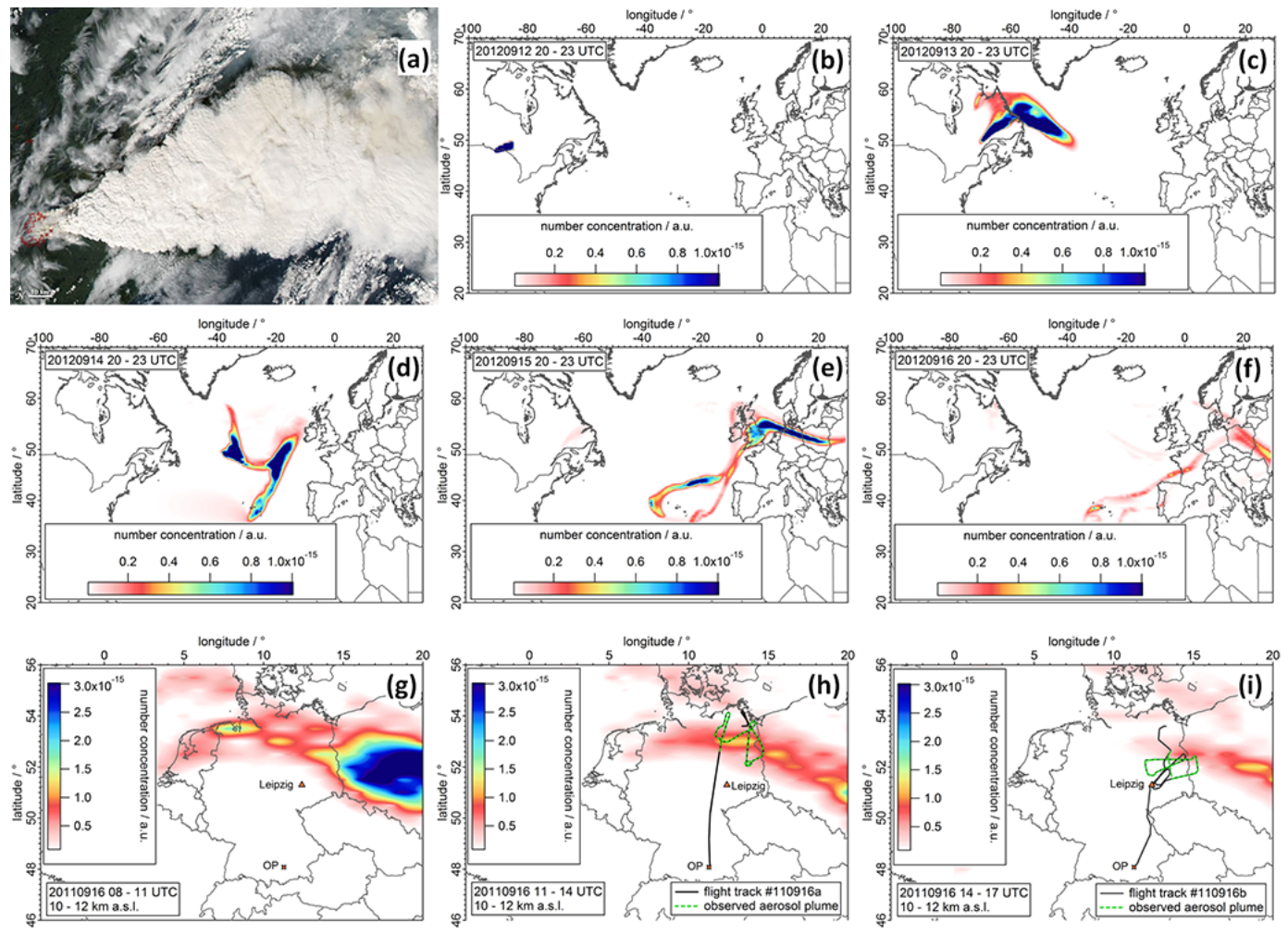

Figure 10. Evolution and dispersion of the Pagami Creek fire plume calculated with HYSPLIT. (a) MODIS picture of Pagami Creek fire in Minnesota, USA on 12 September 2011, 18:50 UTC (NASA images courtesy Jeff Schmaltz, MODIS Rapid Response Team at NASA GSFC. Caption by Michon Scott.); (b-f) Daily evolution of the plume vertically integrated from 6-14 km from 12 September 2011 through to 16 September 2011 for time period 20-23 UTC on each day; (g-i) dispersion of the plume over Germany vertically integrated from 10-12 km for the 16 September 2011, (g): 08:00-11:00 UTC, (h): 11:00-14:00 UTC and (i): 14:00-17:00 UTC and locations of Oberpfaffenhofen (OP; star) and Leipzig (triangle). Green dashed lines in (h) and (i) represent the sequences where the Pagami Creek fire plume was measured.

comparable with the STP $\mathrm{rBC}$ mass concentration in the PBL over Neubrandenburg-Trollenhagen $\left(0.11 \mu \mathrm{g} \mathrm{m}^{-3}\right.$ and $0.05 \mu \mathrm{g} \mathrm{m}^{-3}$; STP) and Oberpfaffenhofen $\left(0.38 \mu \mathrm{g} \mathrm{m}^{-3}\right.$ and $0.96 \mu \mathrm{g} \mathrm{m}^{-3}$; STP) on that day but far larger than the background concentration $\left(<0.01 \mu \mathrm{g} \mathrm{m}^{-3}\right.$; STP $)$ at the same altitude as the plume. Oberpfaffenhofen is located near the metropolitan area of Munich. Therefore these values are representative of a polluted PBL. To put the results of the observed Pagami Creek fire plumes in context to the literature and to other typically expected BC-containing aerosol types, several papers are chosen: biomass-burning plumes from Wyoming (Pratt et al., 2011), biomass burning from North America and Asia (Kondo et al., 2011a), biomassburning and anthropogenic emissions from California (Sahu et al., 2012), biomass-burning and urban emissions from Texas (Schwarz et al., 2008a) and urban emissions from California (Metcalf et al., 2012). In 12-24 h-old biomass-burning plumes at altitudes from ground to roughly $5 \mathrm{~km}$ Kondo et al. (2011a) measured the highest $\mathrm{rBC}$ mass concentration in smoldering burning events $\left(0.27 \mu \mathrm{g} \mathrm{m}^{-3}-1.24 \mu \mathrm{g} \mathrm{m}^{-3}\right.$; STP). Sahu et al. (2012) observed rBC mass concentrations of $0.50 \pm 0.17 \mu \mathrm{g} \mathrm{m}^{-3}$ (STP), while Pratt et al. (2011) reported total $\mathrm{rBC}$ mass concentrations of up to $2 \mu \mathrm{g} \mathrm{m}^{-3}$ in fresh biomass-burning plumes $(\sim 2-120 \mathrm{~min}$ old $)$ in altitudes up to $3.5 \mathrm{~km}$ a.g.l. These concentrations are a factor of 5-60 larger than those found for the aged Pagami Creek fire plume (3-4 day old) in this study. However, the measurements by Pratt et al. (2011) were taken at altitudes lower than $3.5 \mathrm{~km}$ whereas our measurements were taken above $10 \mathrm{~km}$. These differences, however, may be attributed at least partly to the dilution caused by turbulent mixing and wet removal processes. Besides the emissions of forest fires, preexisting BC particles originating from other sources such as traffic and other anthropogenic combustion processes may contribute to the BC load in forest-fire plumes. However, due to the intensity and the remote location of the fire, this fraction is assumed to be small so that the described characteristics can be considered to be representative of the forest-fire particles.

Besides the rBC mass concentration, the mass size distribution is an important aspect for BC in the atmosphere. As can be seen from Fig. 5, the MMD in the Pagami Creek fire plume is between $120 \mathrm{~nm}$ and $160 \mathrm{~nm}$. These MMDs are smaller than observed by Kondo et al. (2011a) who found MMDs between $177 \mathrm{~nm}$ and $197 \mathrm{~nm}$ in fresh 
Table 3. List of research flights during CONCERT 2011. The lower and upper boundary* of the detected aerosol layers is given for each flight. The Pagami Creek fire plume is written in bold type. OP, Oberpfaffenhofen; NB, Neubrandenburg-Trollenhagen; TRA, Temporary Restricted Area.

\begin{tabular}{|c|c|c|c|c|c|c|}
\hline \multirow[t]{2}{*}{ Flight ID } & \multirow[t]{2}{*}{ Route } & \multirow{2}{*}{$\begin{array}{l}\text { Take-off } \\
\text { time/UTC } \\
\text { hh:mm }\end{array}$} & \multirow{2}{*}{$\begin{array}{l}\text { Landing } \\
\text { time/UTC } \\
\text { hh:mm }\end{array}$} & \multicolumn{2}{|c|}{ Presence of elevated layers } & \multirow{2}{*}{$\begin{array}{c}\text { Average } \mathrm{rBC} \text { mass } \\
\text { concentration in the } \\
\text { measured } \mathrm{SP} 2 \text { size range } \\
\text { between } 80<D_{\mathrm{rBC}}<440 \mathrm{~nm} \\
(\mathrm{STP}) / \mathrm{ng} \mathrm{m}^{-3}\end{array}$} \\
\hline & & & & $\begin{array}{c}\text { Lower } \\
\text { boundary/km }\end{array}$ & $\begin{array}{c}\text { Upper } \\
\text { boundary/km }\end{array}$ & \\
\hline \multirow[t]{6}{*}{$\# 110907 \mathrm{a}$} & OP - Leipzig - OP & $06: 21$ & $07: 53$ & & & \\
\hline & & & & 2.6 & 3.0 & 2.3 \\
\hline & & & & 3.7 & 5.3 & 3.1 \\
\hline & & & & 3.4 & 3.9 & 2.7 \\
\hline & & & & 2.0 & 3.2 & 2.0 \\
\hline & & & & 10.1 & 10.7 & 107.6 \\
\hline \multirow[t]{5}{*}{ \#110916a } & $\mathrm{OP}-$ Mecklenburg - NB & $10: 48$ & $13: 20$ & & & \\
\hline & & & & 1.8 & 2.0 & 17.3 \\
\hline & & & & 2.2 & 3.4 & 89.6 \\
\hline & & & & 3.4 & 4.5 & 32.4 \\
\hline & & & & 10.1 & 11.6 & $27.6-294.2$ \\
\hline \multirow[t]{4}{*}{$\# 110916 b$} & NB - Leipzig - OP & $14: 54$ & $17: 48$ & & & \\
\hline & & & & 2.0 & 3.3 & 74.3 \\
\hline & & & & 8.7 & 9.5 & 42.1 \\
\hline & & & & 10.9 & 11.3 & $64.1-214.9$ \\
\hline \multirow[t]{5}{*}{ \#110917a } & OP - Hamburg - Brandenburg - OP & 11:05 & $13: 54$ & & & \\
\hline & & & & 2.2 & 3.0 & 75.8 \\
\hline & & & & 3.0 & 4.3 & 54.6 \\
\hline & & & & 4.6 & 5.7 & 5.9 \\
\hline & & & & 2.1 & 3.6 & 105.3 \\
\hline \multirow[t]{2}{*}{ \#110922a } & OP - Frankfurt - Bergen & 07:03 & 09:18 & & & \\
\hline & & & & 4.7 & 5.4 & 424.8 \\
\hline \multirow[t]{2}{*}{$\# 110922 b$} & Bergen - OP & $10: 20$ & 13:20 & & & \\
\hline & & & & 6.5 & 6.9 & 155.4 \\
\hline \multirow[t]{4}{*}{ \#110924a } & OP - TRA Weser - OP & 09:44 & 13:12 & & & \\
\hline & & & & 1.7 & 2.7 & 94.3 \\
\hline & & & & 3.1 & 4.6 & 11.0 \\
\hline & & & & 1.8 & 4.9 & 6.7 \\
\hline \multirow[t]{3}{*}{$\# 110927 \mathrm{a}$} & OP - TRA Weser - OP & $06: 57$ & $10: 27$ & & & \\
\hline & & & & 1.5 & 2.7 & 131.4 \\
\hline & & & & 2.7 & 4.6 & 12.3 \\
\hline \multirow[t]{2}{*}{$\# 110929 \mathrm{a}$} & OP - Catania & $08: 52$ & $12: 19$ & & & \\
\hline & & & & 3.3 & 3.3 & 17.3 \\
\hline \multirow[t]{5}{*}{$\# 110930 \mathrm{a}$} & Catania - Stromboli - Etna - Catania & $06: 34$ & 09:34 & & & \\
\hline & & & & 0.4 & 2.2 & 231.3 \\
\hline & & & & 0.9 & 0.9 & 267.2 \\
\hline & & & & 3.5 & 3.5 & 4.1 \\
\hline & & & & 3.0 & 3.0 & 4.8 \\
\hline \multirow[t]{2}{*}{$\# 110930 \mathrm{~b}$} & Catania - OP & $10: 55$ & $14: 45$ & & & \\
\hline & & & & 2.0 & 3.3 & 9.7 \\
\hline
\end{tabular}

* The boundaries are derived from the in situ measurements, representing the minimal vertical depth of the layers. 


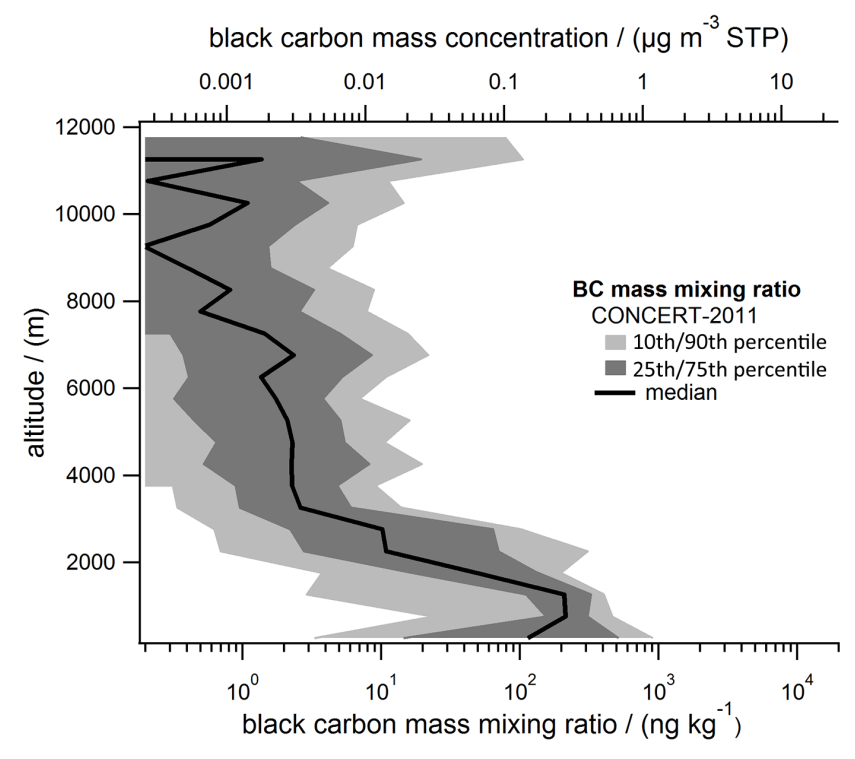

Figure 11. Vertical profile (STP) of the $\mathrm{rBC}$ mass mixing ratio (MMR) and $\mathrm{rBC}$ mass concentration (M) for all flights during CONCERT 2011 measured with the SP2 as median (black), 25th/75th percentile (dark grey), and 10th/90th percentile (light grey) for $500 \mathrm{~m}$ vertical intervals and a temporal resolution of $10 \mathrm{~s}$. Values are valid for the approximate size range of $80-440 \mathrm{~nm}$. The mass mixing ratio MMR was calculated from the mass concentration $m$ $\left(\mathrm{MMR}\left[\mathrm{ng} \mathrm{kg}^{-1}\right]=\mathrm{m}\left[\mathrm{ng} \mathrm{m}^{-3}\right] / 1.29\left[\mathrm{~kg} \mathrm{~m}^{-3}\right]\right)$.

biomass-burning plumes (age < 1 day, origin: North America) and between $176 \mathrm{~nm}$ and $238 \mathrm{~nm}$ in aged biomassburning plumes (age: 2-3 days, origin: Asia). MMDs in biomass-burning plumes observed at altitudes between $0 \mathrm{~km}$ and $3.5 \mathrm{~km}$ a.g.l. in California by Sahu et al. (2012) are $193 \pm 16 \mathrm{~nm}$. Schwarz et al. (2008a) observed MMDs of roughly $160-180 \mathrm{~nm}$ for urban emissions and roughly 200-220 nm for biomass-burning aerosol, while Metcalf et al. (2012) observed modes of roughly $120-140 \mathrm{~nm}$ for boundary layer aerosol and roughly $160 \mathrm{~nm}$ for freetropospheric aerosol during airborne measurements in the Los Angeles Basin. Moteki et al. (2012) and Oshima et al. (2012) describe the wet removal of rBC during transport. A size-dependent wet removal (Moteki et al., 2012) can shift the MMD of aged BC layers towards smaller particle sizes and might cause differences in observed MMDs for BC particle populations with varying exposure to wet removal conditions during the transport as potential reason for the observed differences. They observed, for instance, a decrease from $127 \mathrm{~nm}$ to $97 \mathrm{~nm}$ with decreasing transport efficiency for the count median diameter.

Pratt et al. (2011) observed with their SP2 average BC mass fractions of $0.3-34 \%$ in fresh biomass-burning plumes with the largest part of the mass (60-90\%) being nonrefractory organic material. Comparably high mass fractions of organic material are also reported by Kondo et al. (2011a) who find an organic fraction of 56-92\% and a BC mass frac- tion of 1.7-4.9\%. The values from Kondo et al. (2011a) are comparable to findings from Sahu et al. (2012) presenting $<5 \%$ BC mass fractions. The higher amount of OC compared to $\mathrm{BC}$ can be explained by emission factors, which are $0.2 \mathrm{~g} \mathrm{BC}$ and $7.8 \mathrm{~g} \mathrm{OC}$ per kg burned mass for boreal coniferous forests (McMeeking, 2008; Wiedinmyer et al., 2011). In our study, the volume fraction for rBC-containing particles derived from the SP2 for the 14 considered sequences is $2.5-3.9 \%$ in the described size range. No measurements of organic material were performed but we have to assume that in our case $\mathrm{OC}$ is also a major constituent in terms of mass fraction.

\subsubsection{Total particle number size distributions}

The comparison of the total aerosol number size distributions, including BC-free particles (representing the largest fraction, and a minor fraction of BC-containing particles), of the Pagami Creek fire plume with measurements in clean UTLS "background" air (Fig. 6) exhibits one striking feature: the Aitken and accumulation modes give roughly comparable contributions to particle number concentration in the Pagami Creek fire cases, while the accumulation mode has a very minor contribution in the background case. On 16 September 2011, no particles larger than $400 \mathrm{~nm}$ were present in the background air, while particles of $1-2 \mu \mathrm{m}$ in diameter were detected in the Pagami Creek fire plume. In all Pagami Creek fire plume cases the accumulation mode is strongly enhanced compared to the background sample. Deviating from the monomodal structure of the background aerosol, the particles larger than $0.14 \mu \mathrm{m}$ can be attributed to the presence of forest-fire aerosol. Our results of number size distributions of biomass-burning plumes as well as measurements from the SAMUM-2 field experiment at 0.8 $4.2 \mathrm{~km}$ altitude (Weinzierl et al., 2011), the SAFARI 2000 field experiment at roughly $2-5 \mathrm{~km}$ altitude (Haywood et al., 2003), the LACE 98 field experiment at 3-5 km altitude (Fiebig et al., 2003) and the ICARTT-ITOP field experiment at $3-9 \mathrm{~km}$ altitude (Petzold et al., 2007) show that in all biomass-burning aerosol cases, an enhanced accumulation mode is present. Especially in the ICARTT-ITOP case where a 6-9 day-old Canadian forest-fire aerosol layer over Europe was investigated, the bimodal structure of the size distribution is very pronounced and similar CMDs are found as in our case. By approximating STP conditions, results from LACE 98 (Fiebig, 2001) exhibit a bimodal structure with similar CMDs as well as with total number concentration about 2-9 times higher than in the Pagami Creek fire plume (not shown). Compared to our results, the SAMUM-2 case (3-6 day old) shows a similar CMD for particles $>0.14 \mu \mathrm{m}$ but the mode for particles $<0.14 \mu \mathrm{m}$ is not as enhanced. In addition, Weinzierl et al. (2011) reported a significant coarse mode fraction for data collected during the SAMUM-2 field experiment attributable to mineral dust. In contrast we observed no significant amount of aerosol particles larger $1 \mu \mathrm{m}$. 

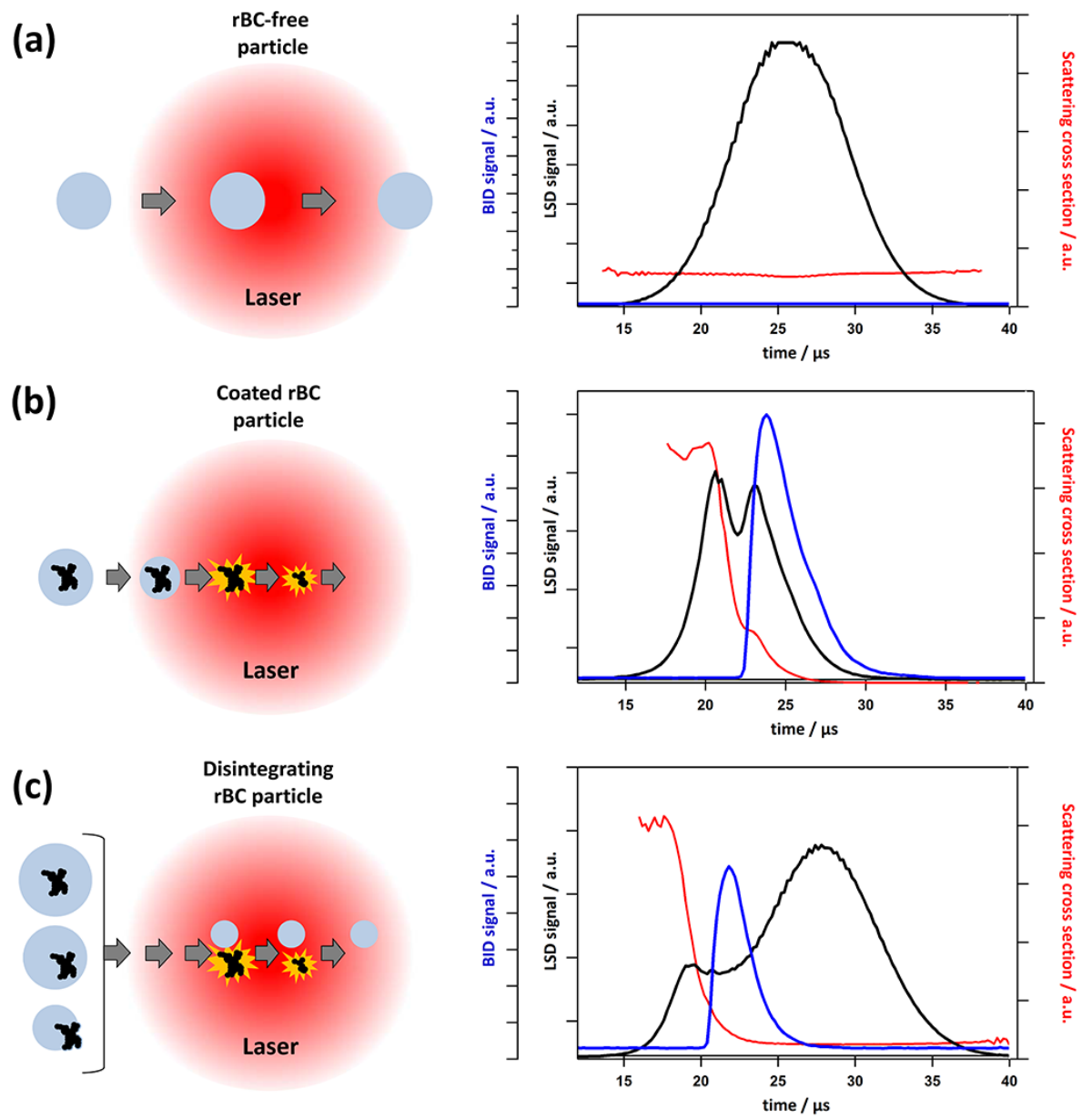

Figure 12. SP2 raw signals for selective particles with LSD signal (black) and BID signal (blue) and the scattering cross-section (red) for (a) - an rBC-free particle, (b) - a coated rBC particle and (c) - a disintegrating rBC particle. Schematics for the particle-laser interaction for each raw signal plot are shown on the left. For the disintegrating rBC particle in (c) several initial structures are possible: a very thickly coated $\mathrm{rBC}$ particle (top); a thickly coated particle with an eccentrically located $\mathrm{rBC}$ core (middle); an $\mathrm{rBC}$ particle located at the surface of an rBC-free particle (bottom). For depiction purposes the size of the schematically-shown particles (left) is enlarged compared to the laser diameter. The scattering cross-section was obtained by dividing the scattering signal by the laser intensity profile. The incandescence is indicated by yellow stars.

Results from SAFARI 2000 show only the accumulation mode since no measurements or extrapolations for particles $<100 \mathrm{~nm}$ were performed. Furthermore, the SAFARI 2000 size distribution was scaled to quantities found in our and other studies, since in Haywood et al. (2003) the size distribution is given as a normalized distribution. In summary, our observations are similar to biomass-burning number size distributions observed previously, especially for ICARTT-ITOP and LACE 98, indicating similar origins, source material, environmental and burning conditions or transportation. The aerosol layers often show similar modes in the accumulation mode size range. Thus, a dominant accumulation mode and a relatively large modal diameter $(\sim 200-400 \mathrm{~nm})$ seem to be common features of forest-fire aerosols.

\subsubsection{Coating thickness}

The coating thickness of $\mathrm{BC}$-containing particles in biomassburning plumes has previously been reported in the literature. Akagi et al. (2012) observed for a chaparral fire that $85 \%$ of the $\mathrm{rBC}$ cores may have been thickly coated $4 \mathrm{~h}$ after emission, i.e., with shell/core diameter ratios $\left(D_{\text {opt }} / D_{\mathrm{rBC}}\right)>\sim 2$ based on the time delay approach. Kondo et al. (2011a) observed rBC particles in biomass-burning plumes with shell/core ratios of $D_{\mathrm{opt}} / D_{\mathrm{rBC}}=1.3-1.6$ in biomass-burning plumes, based on the LEO-fit approach. These values are somewhat lower than our observations (Sect. 3.1), which may be related to differences in the properties of the freshly emitted particles or continued mass acquisition of the $\mathrm{BC}$ particles during the long-range transport in the Pagami Creek fire plume. The coatings reported for 
the $\mathrm{BC}$ particles from forest fires in all three studies discussed here are substantial. This is in contrast to BC particles emitted from diesel engines and wood burning for residential heating, which emit particles with very little and moderate coatings, respectively, and also the median coating thickness observed in aged aerosols typically remains clearly below $100 \mathrm{~nm}$ (Laborde et al., 2013, and references therein).

\subsection{Morphology and disintegration of black carbon particles}

The interaction of BC-containing particles with solar radiation depends on their morphology and mixing state with light-scattering aerosol components (Kahnert et al., 2012). The coating thickness values reported in the previous section were inferred assuming a concentric-spheres, core-shell morphology for the $\mathrm{BC}$ core and a purely scattering coating. However, the $\mathrm{BC}$ cores of combustion particles are fractallike or compact aggregates and the $\mathrm{BC}$ can be mixed with light-scattering material in different ways, including, e.g., surface contact of the $\mathrm{BC}$ with the scattering components, full immersion of the $\mathrm{BC}$ in the scattering component or immersion of the scattering components in the $\mathrm{BC}$ aggregate (Scarnato et al., 2013). Previous laboratory and field experiments have shown that the SP2 signals of BC-containing particles can sometimes give indirect evidence of how the $\mathrm{BC}$ core is mixed with the scattering components beyond just quantifying the coating thickness (Sedlacek et al., 2012; Moteki and Kondo, 2007).

Figure 12 schematically shows the particle-laser interaction of different particle types and the corresponding SP2 signals including the time-resolved scattering cross-section as inferred from the raw LSD signal, according to the method described in Laborde et al. (2012a). For BC-free particles (Fig. 12a) the LSD signal usually follows an almost Gaussian shape. The LSD signal is directly proportional to the laser intensity profile along the flight path of the particle through the laser beam, because the size and thus also the scattering cross-section of a non-absorbing particle remains unchanged during laser transition. The maximum of the LSD signal from $\mathrm{BC}$-free particles occurs at the center of the laser beam (here at time $26 \mu$ s; Fig. 12a).

In contrast, the size of a BC-containing particle is reduced during laser transition, first through evaporation of non-refractory coating material followed by evaporation of $\mathrm{BC}$, which has a higher boiling point. Figure 12b shows typical SP2 signals of BC-containing particles with a mediumthick coating. The LSD responds with an increasing signal when the particle enters the laser beam and scatters the laser light with a constant scattering cross-section. Traveling further into the laser beam, the $\mathrm{BC}$ core absorbs the laser radiation and heats up. As a consequence, the coating evaporates and causes a decrease in the scattering cross-section. This often results in a first local maximum of the LSD signal (here at time $21 \mu \mathrm{s}$; Fig. 12b). After complete evaporation of the coat- ing, the scattering cross-section of the particle stabilizes for a short time and the LSD signal raises again, because the laser intensity increases still (time range $22-23 \mu$ s; Fig. 12b). The $\mathrm{BC}$ core heats up further, until it reaches the boiling point of BC. The thermal radiation, emitted by the particle and detected by the incandescence detectors, now reaches its maximum (here at time $24 \mu \mathrm{s}$; Fig. 12b), and the BC core evaporates, resulting in a fast decrease of the $\mathrm{BC}$ mass and thus also the scattering cross-section of the residual particle, which is reflected in a fast decrease of the BID and LSD signals, respectively. Consequently, the LSD signal can have a second local maximum around the peak of the BID signal (here at time $23 \mu \mathrm{s}$; Fig. 12b). This second local maximum is typically higher than the first local maximum of the LSD signal for $\mathrm{BC}$ particles with a thin or medium coating, such that the global maximum of the LSD signal occurs at about the same time as the peak of the BID signal. For thickly coated BC particles, the first local maximum of the LSD signal is typically higher than the second local maximum, such that the global maximum occurs before the peak of the BID signal. Moteki and Kondo (2007) have shown that the time lag between the peaks of the LSD and the BID signals gives crude information about the mixing state of BC-containing particles, where values $>\sim 2 \mu \mathrm{s}$ are associated with thick coatings, while values $<\sim 2 \mu$ s are associated with thin to medium coatings.

However, particles that disintegrate in the laser beam of the SP2 have also been reported in the literature (Moteki and Kondo, 2007; Sedlacek et al., 2012). Disintegration occurs before the $\mathrm{BC}$ core reaches its boiling point and results in a $\mathrm{BC}$-free fragment, which remains stable after disintegration, and a $\mathrm{BC}$ fragment that eventually evaporates. Figure $12 \mathrm{c}$ shows the SP2 signals of such a disintegrating BC-containing particle. Disintegration can be identified by the fact that the LSD signal does not fully disappear after evaporation of the $\mathrm{BC}$ core. More precisely, the scattering cross-section stabilizes again after the peak BID signal, as the BC-free fragment does not evaporate any further (here at time > $24 \mu$ s; Fig. 12c). Furthermore, the stable scattering cross section in both the leading and trailing edges of the laser beam is a key feature that distinguishes disintegrating particles from coincidence of a BC-containing and a BC-free particle (the position dependent correction for the laser beam intensity would fail for coincident particles, that are, while simultaneously being in the laser beam, not exactly in the same position; this would cause an apparent time dependence of the inferred leading and/or trailing edge scattering cross section for coincident particles). The BC-free fragment of a disintegrated particle, which behaves as a BC-free particle after its separation, causes another local maximum of the LSD signal at the center of the laser beam (here at time $28 \mu \mathrm{s} ;$ Fig. 12c). This local maximum of the LSD signal from the $\mathrm{BC}$-free fragment can be the global maximum if the BC-free fragment is a substantial portion of the original particle. In this case the time lag between the peaks of the LSD and the BID signals 
becomes negative as the peak of the BID signal normally occurs before the center of the laser beam.

Sedlacek et al. (2012) have reported, for the first time, the identification of disintegrating particles through negative lag times. However, in our study, only a minor fraction of all disintegrating particles could be identified via a negative lag time because most of the disintegrating particles either exhibited a positive lag time or because the peak of the LSD signal, and with that, also the lag time, were not defined due to LSD detector saturation. Therefore, the time-dependent (positiondependent) scattering cross-section, as inferred from the raw LSD signal, according to the method described in Laborde et al. (2012a), was used here to identify disintegrating particles. Specifically, the scattering cross-section measured in the trailing edge of the laser beam (at the position with $3 \%$ of the maximum laser power) was used to determine for all BC-containing particles whether a detectable BC-free fragment (producing an LSD signal above background noise) remained left in the trailing edge of the laser beam. The scattering cross-section measured in the leading edge of the laser beam (at the position with $3 \%$ of the maximum laser power) was used to determine the size of the undisturbed particles, in order to further investigate the influence of particle size on disintegration. The relation of the scattering cross-section at the leading edge and at the trailing edge of the laser beam for BC-containing particles is shown Fig. 13a for a sequence measured in the Pagami Creek fire plume (11:36-11:46 UTC, 16 September 2011). The trailing edge LSD signal indicates that about $50 \%$ of the BC-containing particles in the plume with particle size of about $D_{\mathrm{opt}}=300 \mathrm{~nm}$ disintegrated in the laser beam, leaving a detectable BC-free fragment. The fraction of disintegrating particles increased with increasing particle size, so that $>90 \%$ of the $\mathrm{BC}$ particles disintegrated at large sizes $\left(D_{\text {opt }}>\sim 480 \mathrm{~nm}\right)$. Conversely, the majority of the smaller particles $\left(D_{\text {opt }}<\sim 300 \mathrm{~nm}\right)$ showed no disintegration characteristics. However it cannot be distinguished if they actually evaporated completely or if potential BC-free fragments just remained below the detection limit of the LSD. Overall $\sim 40-50 \%$ of all detected BC-containing particles were identified as disintegrating particles with the trailing edge LSD-signal method. Data points shown in Fig. 13a remaining on or above the $1: 1$ line are attributable to the coincidence of a BC-free and a BC-containing particle, marked by the grey pattern. However, coincidence accounts for only a very low fraction of the data points.

Only 3.5-6.8\% (median: $4.6 \%$ ) of all BC particles, corresponding to roughly 5-20\% of all identified disintegrating BC particles, exhibited a negative lag time in this study. This shows that the lag-time method only provides a lower limit for the total fraction of disintegrating particles. The success rate of the lag-time method for the identification of disintegrating particles depends on particle and instrument properties such as, e.g., the particle size and the saturation level of the LSD.
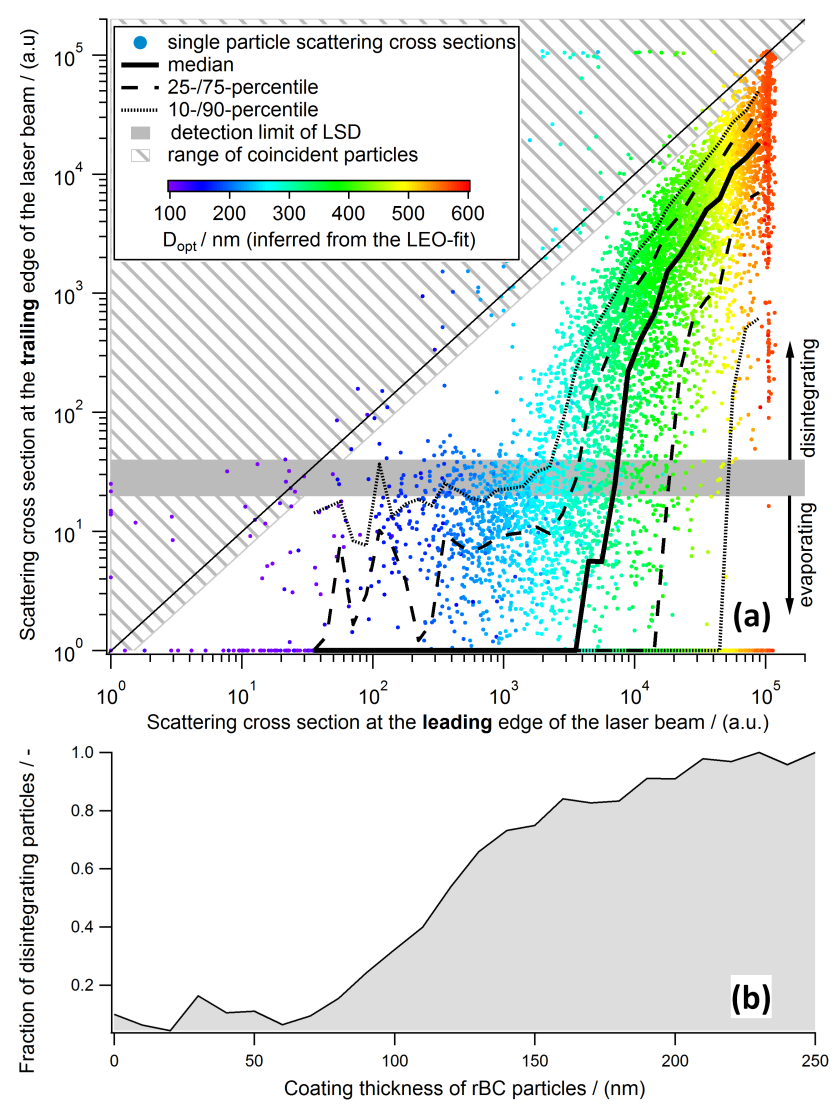

Figure 13. (a) Relation of the scattering cross-section at the leading edge and at the trailing edge of the laser beam for BC-containing particles (dots; color-coded for $D_{\text {opt }}$ determined by the LEO-fit approach) with median (solid black line), 25th/75th percentiles (dashed black lines) and 10th/90th percentiles (dotted black lines) shown for a sequence measured in the Pagami Creek fire plume (11:36-11:46 UTC, 16 September 2011). The grey bar represents the detection limit of the LSD while the grey pattern indicates the range where the data points are attributable to coincidence of $\mathrm{BC}$ free and BC-containing particles in the laser beam (black line: $1: 1$ line). Particles with scattering cross-section at the trailing edge of the laser beam remaining above the detection limit of the LSD indicate the disintegration of BC-containing particles. (b) Fraction of disintegrating particles to all $\mathrm{rBC}$-containing particles as function of their coating thickness for the same sequence as in (a).

Sedlacek et al. (2012) observed disintegrating particles during a ground-based field campaign in summer 2011. More than $60 \%$ of BC-containing particles in the forest-fire aerosol plume from several wildfires east of Lake Winnipeg and into western Ontario on 30 July were disintegrating BC particles, exhibiting negative lag times in the SP2. Our observations show for the first time the occurrence of disintegrating $\mathrm{BC}$ particles in high-altitude BC layers (40-50\% of all detected $\mathrm{BC}$-containing particles, according to the trailing-edge LSD signal method).

Sedlacek et al. (2012) suggested that disintegrating particles are associated with a particular particle morphology, 
where the $\mathrm{BC}$ is located near or at the surface of the $\mathrm{BC}$ containing particles. Moteki and Kondo (2007) also reported the occurrence of disintegrating particles in laboratory experiments with graphitic cores that were coated with glycerol or oleic acid. The number fraction of disintegrating particles was mainly a function of overall particle diameter. No disintegration was observed for small sizes, while almost all larger particles disintegrated. The threshold particle diameter for the occurrence of disintegration was 450-600 nm depending on the coating type. Moteki and Kondo (2007) speculated that disintegration might be associated with eccentrically positioned BC cores in their case, while near-surface BC morphology was not expected based on the process applied to coat the $\mathrm{BC}$ cores.

The specific $\mathrm{BC}$ particle morphology, i.e., core-shell versus near-surface $\mathrm{BC}$, is relevant because the light-absorption efficiency enhancement effect by light-scattering coatings internally mixed with $\mathrm{BC}$ depends on the coating volume fraction as well as the particle morphology. Coatings with $D_{\text {opt }} / D_{\mathrm{rBC}}$-ratios of 2 can already enhance the light-absorption by the BC cores by $100 \%$ (Schwarz et al., 2008b; Shiraiwa et al., 2010), while the relation between the coating thickness and the enhancement factor is not linear and saturation occurs above a certain threshold. The high $D_{\text {opt }} / D_{\mathrm{rBC}}$ ratios observed in the Pagami Creek fire plume imply that substantial light-absorption enhancement effects are expected, though large uncertainties of this effect remain (e.g., Cappa et al., 2012). Sketches of three conceivable morphologies of disintegrating $\mathrm{BC}$-containing particles are shown on the left side of Fig. 12c: a concentric core-shell, an eccentric core-shell or a near-surface BC/attached BC morphology. Light-scattering matter simply attached to a $\mathrm{BC}$ core causes very little enhancement of the light-absorption efficiency (Liu and Mishchenko, 2007; Scarnato et al., 2013). In contrast, a substantial light-absorption efficiency enhancement can be expected for coated BC-containing particles with a concentrically or eccentrically positioned core.

We note here that disintegrating particles might also complicate the interpretation of the Soot-Particle Aerosol Mass Spectrometer (SP-AMS; Onasch et al., 2012) measurements because the BC-free fragment would not be evaporated by the laser. This should be further investigated with specific laboratory experiments involving biomass-burning aerosol and the SP-AMS.

A process that can produce near-surface $\mathrm{BC}$ morphologies is coagulation of almost bare $\mathrm{BC}$ aggregates with $\mathrm{BC}$-free particles. Condensation of secondary organic or inorganic aerosol components on $\mathrm{BC}$ particles can either result in particles with core-shell morphology (concentric or eccentric) or with near-surface BC morphology. Adachi et al. (2010) proposed a mechanism producing near-surface $\mathrm{BC}$ particles via condensation processes, which involves condensation of organic material onto nascent $\mathrm{BC}$ that effectively preserves the aggregate of primary BC particles in an un-collapsed form, followed by further mass acquisition via condensation, pref- erentially onto the more organic portion of the particle. Based on our observations in the aged Pagami Creek fire plume, disintegration was associated with large BC-containing particles (overall optical diameter $>\sim 300 \mathrm{~nm}$; see above). These large particles generally had a very low $\mathrm{rBC}$ mass fraction since the majority of the $\mathrm{rBC}$ cores were $<130 \mathrm{~nm}$ in diameter. They can be the result of extensive condensation of secondary aerosol components onto the nascent $\mathrm{BC}$ aggregates or of coagulation of BC-particles with large BC-free particles during transport. Indeed, the initial plume was highly concentrated such that both processes are likely to occur during aging of the $\mathrm{BC}$ particles in the plume. Thus, it is in principle possible that both $\mathrm{BC}$ particle types with near-surface $\mathrm{BC}$ or core-shell morphology are present in the aged plume. However, the observed number fraction of disintegrating particles is for the most part a function of overall particle size, indicating that disintegration was possibly just the result of very thick coatings, as reported in the laboratory study by Moteki and Kondo (2007). Figure 13b shows the fraction of disintegrating particles to all $\mathrm{rBC}$-containing particles as function of their coating thickness for the same sequence as shown in Fig. 13a (11:36-11:46 UTC, 16 September 2011). The increasing fraction of disintegrating particles with respect to all rBC-containing particles as a function of increasing coating thickness supports the assumption that thick coatings trigger the disintegration. At a coating thickness of about $120 \mathrm{~nm} 50 \%$ of the rBC-containing particles produce an LSD signal above background noise in the trailing edge of the laser beam. For particles with coating thicknesses $>200 \mathrm{~nm}$, more than $90 \%$ of the rBC-containing particles disintegrate. Moteki et al. (2014) showed with controlled laboratory experiments that attached-type rBC particles can be identified by insignificant evaporation before incandescence onset. The dominant fraction of the disintegrating $\mathrm{rBC}$-containing particles observed in the Pagami Creek fire plume exhibited substantial coating evaporation, such as the example particle shown in Fig. 12c, which is clear evidence that those rBCcontaining particles had a coated-type morphology.

The specific features of the particles in the aged Pagami Creek fire plume observed in this study are the enhanced size of all particles (Fig. 6) and the enhanced coating thickness of BC-containing particles (Fig. 7a) compared to the observations outside the plume. Both can be attributed to extensive coagulation and/or condensation in the forest-fire plume. The very thick coatings of $\mathrm{BC}$ particles in the forest-fire plume will influence their light-absorption properties. Furthermore, they will also influence their interaction with clouds. They are expected to be good cloud condensation nuclei through the mere size effect as well as the additional hygroscopic water uptake by the coating (e.g., McMeeking et al., 2011; Laborde et al., 2013; Liu et al., 2013). Furthermore, the mixing state of the $\mathrm{BC}$ with organic and inorganic matter might have an influence on the ice-nucleation efficiency of the particles and is thus relevant for the indirect aerosol effect (Hoose and Möhler, 2012). 
It is important to consider large particle size when assessing the radiative impact of such plumes by direct lightscattering of solar radiation. When assessing the radiative impact via absorption of solar radiation, it is recommended, based on the above discussion about the morphology of BC particles, to consider the light-absorption enhancement effect that is expected to occur for thickly coated BC particles with core-shell morphology.

The first two reports of disintegrating $\mathrm{BC}$ particles in ambient aerosols are from forest-fire plumes (Sedlacek et al., 2012 and this study). The question if disintegrating particles are uniquely or predominantly associated with biomassburning aerosol remains to be addressed. A UTLS background sequence on 16 September 2011 showed an insignificant amount of disintegrating particles $(<1 \%)$. The fact that biomass-burning $\mathrm{BC}$ particles often exhibit thicker coatings compared to $\mathrm{BC}$ particles from, e.g., diesel engines, even allowing for coating acquisition during atmospheric aging (e.g., Laborde et al., 2013), might be a reason for the preferential occurrence of disintegrating particles in biomassburning aerosol.

\subsection{Black carbon import into the UTLS by the Pagami Creek fire in comparison to aviation}

In this section we present two estimates for determining the primary emissions from the Pagami Creek fire (first estimate) and the import of $\mathrm{BC}$ from the fire to the UTLS region (second estimate).

First, we estimate the total $\mathrm{OC}$ and $\mathrm{BC}$ emissions of the Pagami Creek fire (Fig. 14a) based on the burned area, the wood mass per area and the emission factor of boreal needle-leaf forests based on the values presented in Wiedinmyer et al. (2011). These consist of BC and OC emission factors for boreal coniferous forests $(0.2 \mathrm{~g}$ per $\mathrm{kg}$ biomass burned and $7.8 \mathrm{~g}$ per $\mathrm{kg}$ biomass burned, respectively; McMeeking, 2008) and fuel loadings for North American boreal forests $\left(25 \mathrm{~kg} \mathrm{~m}^{-2}\right.$; Akagi et al., 2011, and references therein) are combined with the burned area $\left(\sim 350 \mathrm{~km}^{2}\right.$; US Forest Service), resulting in roughly $2 \times 10^{3} \mathrm{Mg} \mathrm{BC}$ and $68 \times 10^{3} \mathrm{Mg}$ OC emitted from the Pagami Creek fire. This estimate depends strongly on the assumptions made for the burned area and the applied emission factors and must be considered with caution, implying large uncertainties. A large fraction of these primary emissions will fall out quickly by, e.g., wet deposition (see Sect. 4.1), will be transported to altitudes below $8 \mathrm{~km}$ (see Fig. 3; Mattis et al., 2008; Weinzierl et al., 2011) or will not even enter the free troposphere. The fraction of the emissions entering the upper troposphere is more relevant in terms of its impact on the radiation budget due to longer life time and the possibility of long-range transport.

To assess the $\mathrm{BC}$ import of the Pagami Creek fire to the UTLS directly, we create a second estimate. Assuming a homogeneously distributed aerosol layer, we can approximately

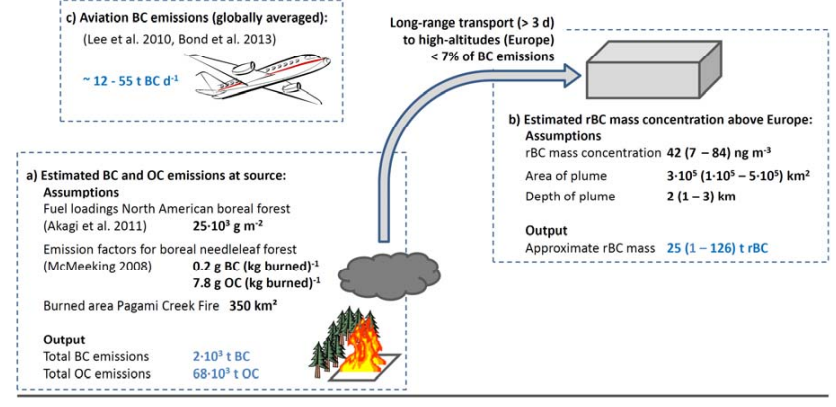

Figure 14. Schematic of the BC mass import of the Pagami Creek fire: (a) calculation of total $\mathrm{BC}$ and $\mathrm{OC}$ emissions from the fire based on fuel loadings, emission factors and burned area; (b) BC mass import into the UTLS region above Europe based on the dispersion of the plume and measured $\mathrm{rBC}$ mass concentrations as a best guess (and total range); (c) comparison to daily $\mathrm{BC}$ emissions from global aviation.

derive the BC mass import from the Pagami Creek fire event into the UTLS region above Europe (Fig. 14b) from our measurements and dispersion model simulations. The area of the aerosol layer is deduced from the HYSPLIT dispersion calculation by sizing the plume area for 15 September 2011 (20:00-23:00 UTC) by assuming a plume concentration threshold ( 0.1 a.u.; see Fig. 10) and a reasonable uncertainty (area: $(3 \pm 2) \times 10^{5} \mathrm{~km}^{2}$; Sect. 3.3). This plume area is representative of the plume observed $12 \mathrm{~h}$ later above Europe based on observations from IASI (Sect. 3.3) and GOME (Sect. 3.3). The depth of the aerosol layer is deduced from the lidar observations (depth: $2 \pm 1 \mathrm{~km}$; Sect. 3.1). Thus, the volume of the plume is derived as $0.1-1.5 \times 10^{6} \mathrm{~km}^{3}$ (best estimate: $0.6 \times 10^{6} \mathrm{~km}^{3}$ ). Furthermore, we use the rBC mass concentration from our measurements at the edge of the plume (7-84 $\mathrm{ng} \mathrm{m}^{-3}$; median of measurement sequences: $42 \mathrm{ng} \mathrm{m}^{-3}$; at ambient conditions). From these data we obtain a best estimate for the $\mathrm{BC}$ total mass import into the high-altitude aerosol layer above Europe of $25 \mathrm{Mg} \mathrm{BC}$, ranging from $1-126 \mathrm{Mg} \mathrm{BC}$. This estimate depends strongly on the plume area at the time of measurements, which in turn depends on the assumed duration of the emission in the dispersion calculations. Nevertheless, we show in Sect. 3.3 that the duration of the emissions used in the simulation is in good agreement with the observations of the duration of the fire. The local inhomogeneities observed in both the simulation (Fig. 10) and the measurements (Fig. 2) cause large uncertainties in plume area and average concentration. However, the uncertainties of this estimate are smaller than the uncertainties for the theoretical estimate on the direct total emissions of the Pagami Creek fire described above. This is because the input parameters are based on direct measurements and calculations related to the specific event rather than generalized emission factors used in the first estimate. As the dispersion calculation suggests that the measurements took place in the less concentrated tail of the plume, the maximum 
value of $126 \mathrm{Mg} \mathrm{BC}$ might still underestimate the imported BC mass. Nonetheless, it is highly likely that the real BC mass of the Pagami Creek fire plume is within the presented span of $1-126 \mathrm{Mg} \mathrm{BC}$.

Comparing our best estimate of the direct emissions at the source with the best estimate of the BC mass in the plume we observed after 4 days on 16 September 2011, this aerosol layer above Europe contains less than $7 \%$ of the total BC mass emitted by the fire.

These estimates show that singular forest-fire events can be a relevant source for substantial BC loadings in the UTLS region on time scales of at least several days. Aside from forest fires, another (permanent) source of $\mathrm{BC}$ in the UTLS region is emissions from aircraft (Fig. 14c). Lee et al. (2010) estimate the soot (defined as BC + OC) emissions from aviation to $16 \mathrm{Mg} \mathrm{d}^{-1}$. The $\mathrm{BC} / \mathrm{OC}$ ratio for aviationinduced soot is roughly 3.5 (Bond et al., 2004, and references therein). Thus, the estimate of Lee et al. (2010) can be converted to roughly $12 \mathrm{Mg} \mathrm{d}^{-1}$ of BC. Bond et al. (2013) estimate the aviation-induced $\mathrm{BC}$ to be $55 \mathrm{Mg} \mathrm{d}^{-1}$ The $\mathrm{BC}$ emissions from aviation in the UTLS region are even smaller, taking into account that the total aviation-induced emissions contain also emissions during take-off and landing at lower altitudes. Nevertheless, the best guess of the BC mass imported from the Pagami Creek fire to the UTLS region over Europe after several days of transport is of the same magnitude as the daily globally averaged $\mathrm{BC}$ mass emissions from aviation. The comparison of $1-126 \mathrm{Mg} \mathrm{BC}$ in the Pagami Creek fire plume in the UTLS region over Europe to 12$55 \mathrm{Mg} \mathrm{d}^{-1} \mathrm{BC}$ related to aviation shows the relevance of such singular forest-fire events as a source for the import of black carbon into the atmosphere, keeping in mind that the $\mathrm{BC}$ size distribution of aviation-induced $\mathrm{BC}$ shows high concentrations in the smaller size ranges in contrast to forest-fire $\mathrm{BC}$ in the UTLS region. As this result is based on several assumptions, the given values should be considered with caution but do illustrate the potential relevance of forest fires as a source for BC in the UTLS region. A future increase in forest-fire activity due to a changing climate might be of great importance to the BC import into the upper troposphere.

\section{Summary and conclusion}

In the framework of the CONCERT 2011 field experiment we observed numerous elevated aerosol layers over Europe with the DLR research aircraft Falcon. This study focused on the Pagami Creek forest-fire aerosol layer detected accidentally on 16 September 2011 between $10 \mathrm{~km}$ and $12 \mathrm{~km}$ altitude over northeast Germany. From our measurements with the SP2, we derived the median vertical profile of $\mathrm{rBC}$ mass concentration for the entire CONCERT 2011 field experiment, representing an estimate for the typical black carbon mass-mixing ratios in central Europe in September 2011. We discussed the Pagami Creek fire plume with respect to this average situation. To obtain information about the aerosol layer characteristics, refractory black carbon (rBC) mass size distributions and total aerosol particle number size distributions were calculated for different parts of the Pagami Creek fire plume over Europe. The mode parameters of the applied log-normal fits were compared to size distributions of biomass-burning aerosol from other studies. Determining the impact of those elevated aerosol layers on the radiation budget it is essential for investigating the mixing state of the particles. Therefore, the coating thickness of individual aerosol particles was calculated, assuming ideal spherical BC particles coated with a non-absorbing material. Additionally, we provided information about the mixing structure of individual particles, more precisely, whether a BC-containing particle disintegrated in the SP2 laser beam. This effect was recently found in ground-based measurements of forest-fire aerosol and has now been confirmed for the first time for airborne in situ measurements.

In summary, the major findings of this study were as follows:

- The aerosol layer observed on 16 September 2011 is attributed to the Pagami Creek fire in Minnesota, USA, supported among other observations by the measured lidar linear depolarization ratio $(532 \mathrm{~nm})$ of $6-8 \%$, indicating a forest-fire source.

- The total rBC mass concentration of the aged (34 day-old) Pagami Creek fire plume ranged from 0.03$0.35 \mu \mathrm{g} \mathrm{m}^{-3}$ (STP), comparable to rBC mass concentrations typical for moderately-polluted planetary boundary layers. The MMDs of the $\mathrm{rBC}$ size distribution ranged between $120 \mathrm{~nm}$ and $160 \mathrm{~nm}$.

- In contrast to a background air sample showing a monomodal number size distribution, the Pagami Creek fire plume showed a bimodal number size distribution with a pronounced accumulation and Aitken mode.

- The rBC particles in the Pagami Creek fire plume showed coating thicknesses of roughly 50-220 nm with maxima of the histograms between $\sim 80 \mathrm{~nm}$ and $160 \mathrm{~nm}$ (medians of 14 considered sequences: 105-136 nm), whereas fresh PBL aerosol exhibited coatings predominantly $<65 \mathrm{~nm}$ (median: $<20 \mathrm{~nm}$ ). These coatings may modify the $\mathrm{BC}$ radiative forcing, the $\mathrm{BC}$ hygroscopicity, and the efficiency to act as cloud condensation or ice nuclei. Resulting from small $\mathrm{rBC}$ diameters and large coating thicknesses, we observed shell/core ratios of up to 7.4 with median shell/core diameter ratios of $D_{\mathrm{opt}} / D_{\mathrm{rBC}}=3.7,2.8$ and 2.4 at $D_{\mathrm{rBC}}=90 \mathrm{~nm}$, $130 \mathrm{~nm}$ and $170 \mathrm{~nm}$, respectively.

- We showed that the majority of the rBC-containing particles in the Pagami Creek fire plume disintegrated in the SP2 laser beam. Generally, this instrument-specific 
process will not occur without an intense laser beam but it is an indication of either very thickly coated $\mathrm{rBC}$ cores or $\mathrm{rBC}$ cores located near/attached to the surface of rBC-free particles. In this study, the dominant fraction of the disintegrating particles was of the thickly-coated type, for which a light-absorption enhancement can be expected. The question if disintegrating particles are uniquely or predominantly associated with biomass-burning aerosol remains to be addressed. The fact that biomass-burning BC particles often exhibit thick coatings might be a reason for preferential occurrence of disintegrating particles in biomassburning aerosol. When assessing the radiative impact via absorption of solar radiation, it is recommended to consider the light-absorption enhancement effect that is expected to occur for thickly-coated BC particles with core-shell morphology.

- We presented a rough estimate of the BC mass import due to the Pagami Creek fire to the UTLS region above Europe (best estimate: $25 \mathrm{Mg} \mathrm{BC}$ ) and compared it with the daily $\mathrm{BC}$ emissions of global aviation (12$55 \mathrm{Mg} \mathrm{BC}$ ) thereby highlighting the relevance of forest fires as a potential BC source for the upper free troposphere.

In conclusion, the microphysical properties of the observed Pagami Creek fire plume obtained within this case study clarify the relevance of pyro-convection as a particle source and as a cause for long-range transport of forest-fire aerosol layers in the UTLS region. Consequently, this study enables us to assess the impact of this light-absorbing aerosol layer on the radiation budget using radiation transfer calculations. Additional in situ measurements of aerosol layers similar to the presented layer and additional studies of the processes of aerosol transport by pyro-convection to the UTLS region are necessary to globalize the estimate of $\mathrm{BC}$ mass import into the upper troposphere and to reduce uncertainties of model estimates.

Acknowledgements. This work was funded by the Helmholtz Association under grant number VH-NG-606 (HelmholtzHochschul-Nachwuchsforschergruppe AerCARE). M. Gysel was funded by the ERC under grant 615922-BLACARAT. C. Voigt thanks funding by the Helmholtz Association under grant number VH-NG-309. The field experiment was performed within the DLR project CATS. The authors gratefully acknowledge the NASA/GSFC Rapid Response team for the generation of the MODIS picture, NOAA Air Resources Laboratory (ARL) for the provision of the HYSPLIT transport and dispersion model and READY website (http://ready.arl.noaa.gov) used in this publication, the NASA Langley Research Center Atmospheric Science Data Center for providing CALIPSO data, Ether CNES/CNRS-INSU Ether website, http://www.pole-ether.fr for providing the IASI CO information and KNMI for providing the data of the GOME-2 Absorbing Aerosol Index in the framework of the EUMETSAT
Satellite Application Facility on Ozone and Atmospheric Chemistry Monitoring (O3M SAF).

The service charges for this open access publication have been covered by the Research Centre of the Helmholtz Association.

Edited by: N. Riemer

\section{References}

Adachi, K., Chung, S. H., and Buseck, P. R.: Shapes of soot aerosol particles and implications for their effects on climate, J. Geophys. Res.-Atmos., 115, D15206, doi:10.1029/2009JD012868, 2010.

Akagi, S. K., Yokelson, R. J., Wiedinmyer, C., Alvarado, M. J., Reid, J. S., Karl, T., Crounse, J. D., and Wennberg, P. O.: Emission factors for open and domestic biomass burning for use in atmospheric models, Atmos. Chem. Phys., 11, 4039-4072, doi:10.5194/acp-11-4039-2011, 2011.

Akagi, S. K., Craven, J. S., Taylor, J. W., McMeeking, G. R., Yokelson, R. J., Burling, I. R., Urbanski, S. P., Wold, C. E., Seinfeld, J. H., Coe, H., Alvarado, M. J., and Weise, D. R.: Evolution of trace gases and particles emitted by a chaparral fire in California, Atmos. Chem. Phys., 12, 1397-1421, doi:10.5194/acp-12-13972012, 2012.

Andreae, M. O. and Gelencsér, A.: Black carbon or brown carbon? The nature of light-absorbing carbonaceous aerosols, Atmos. Chem. Phys., 6, 3131-3148, doi:10.5194/acp-6-3131-2006, 2006.

Andreae, M. O., Rosenfeld, D., Artaxo, P., Costa, A. A., Frank, G. P., Longo, K. M., and Silva-Dias, M. A. F.: Smoking rain clouds over the Amazon, Science, 303, 1337-1342, doi:10.1126/science.1092779, 2004.

Aquila, V., Hendricks, J., Lauer, A., Riemer, N., Vogel, H., Baumgardner, D., Minikin, A., Petzold, A., Schwarz, J. P., Spackman, J. R., Weinzierl, B., Righi, M., and Dall'Amico, M.: MADE-in: a new aerosol microphysics submodel for global simulation of insoluble particles and their mixing state, Geosci. Model Dev., 4, 325-355, doi:10.5194/gmd-4-325-2011, 2011.

Barnaba, F., Angelini, F., Curci, G., and Gobbi, G. P.: An important fingerprint of wildfires on the European aerosol load, Atmos. Chem. Phys., 11, 10487-10501, doi:10.5194/acp-1110487-2011, 2011.

Bauer, S. E., Menon, S., Koch, D., Bond, T. C., and Tsigaridis, K.: A global modeling study on carbonaceous aerosol microphysical characteristics and radiative effects, Atmos. Chem. Phys., 10, 7439-7456, doi:10.5194/acp-10-7439-2010, 2010.

Baumgardner, D., Popovicheva, O., Allan, J., Bernardoni, V., Cao, J., Cavalli, F., Cozic, J., Diapouli, E., Eleftheriadis, K., Genberg, P. J., Gonzalez, C., Gysel, M., John, A., Kirchstetter, T. W., Kuhlbusch, T. A. J., Laborde, M., Lack, D., Müller, T., Niessner, R., Petzold, A., Piazzalunga, A., Putaud, J. P., Schwarz, J., Sheridan, P., Subramanian, R., Swietlicki, E., Valli, G., Vecchi, R., and Viana, M.: Soot reference materials for instrument calibration and intercomparisons: a workshop summary with recommendations, Atmos. Meas. Tech., 5, 1869-1887, doi:10.5194/amt-51869-2012, 2012.

Bond, T. C., Streets, D. G., Yarber, K. F., Nelson, S. M., Woo, J. H., and Klimont, Z.: A technology-based global inventory of black 
and organic carbon emissions from combustion, J. Geophys. Res.-Atmos., 109, D14203, doi:10.1029/2003jd003697, 2004.

Bond, T. C., Doherty, S. J., Fahey, D. W., Forster, P. M., Berntsen, T., DeAngelo, B. J., Flanner, M. G., Ghan, S., Kärcher, B., Koch, D., Kinne, S., Kondo, Y., Quinn, P. K., Sarofim, M. C., Schultz, M. G., Schulz, M., Venkataraman, C., Zhang, H., Zhang, S., Bellouin, N., Guttikunda, S. K., Hopke, P. K., Jacobson, M. Z., Kaiser, J. W., Klimont, Z., Lohmann, U., Schwarz, J. P., Shindell, D., Storelvmo, T., Warren, S. G., and Zender, C. S.: Bounding the role of black carbon in the climate system: A scientific assessment, J. Geophys. Res.-Atmos., 118, 5380-5552, doi:10.1002/jgrd.50171, 2013.

Buseck, P. R. and Posfai, M.: Airborne minerals and related aerosol particles: Effects on climate and the environment, P. Natl. Acad. Sci. USA, 96, 3372-3379, doi:10.1073/pnas.96.7.3372, 1999.

Cappa, C. D., Onasch, T. B., Massoli, P., Worsnop, D. R., Bates, T. S., Cross, E. S., Davidovits, P., Hakala, J., Hayden, K. L., Jobson, B. T., Kolesar, K. R., Lack, D. A., Lerner, B. M., Li, S.-M., Mellon, D., Nuaaman, I., Olfert, J. S., Petaja, T., Quinn, P. K., Song, C., Subramanian, R., Williams, E. J., and Zaveri, R. A.: Radiative Absorption Enhancements Due to the Mixing State of Atmospheric Black Carbon, Science, 337, 1078-1081, doi:10.1126/science.1223447, 2012.

Damoah, R., Spichtinger, N., Forster, C., James, P., Mattis, I., Wandinger, U., Beirle, S., Wagner, T., and Stohl, A.: Around the world in 17 days - hemispheric-scale transport of forest fire smoke from Russia in May 2003, Atmos. Chem. Phys., 4, 13111321, doi:10.5194/acp-4-1311-2004, 2004.

Damoah, R., Spichtinger, N., Servranckx, R., Fromm, M., Eloranta, E. W., Razenkov, I. A., James, P., Shulski, M., Forster, C., and Stohl, A.: A case study of pyro-convection using transport model and remote sensing data, Atmos. Chem. Phys., 6, 173185, doi:10.5194/acp-6-173-2006, 2006.

de Graaf, M., Stammes, P., Torres, O., and Koelemeijer, R. B. A.: Absorbing Aerosol Index: Sensitivity analysis, application to GOME and comparison with TOMS, J. Geophys. Res.-Atmos., 110, D01201, doi:10.1029/2004jd005178, 2005.

Diehl, T., Heil, A., Chin, M., Pan, X., Streets, D., Schultz, M., and Kinne, S.: Anthropogenic, biomass burning, and volcanic emissions of black carbon, organic carbon, and $\mathrm{SO}_{2}$ from 1980 to 2010 for hindcast model experiments, Atmos. Chem. Phys. Discuss., 12, 24895-24954, doi:10.5194/acpd-12-24895-2012, 2012.

Draxler, R. R. and Hess, G. D.: Description of the HYSPLIT_4 modelling system, NOAA Technical Memorandum ERL ARL224, Air Resources Laboratory, Silver Spring, Maryland, 1997.

Draxler, R. R. and Hess, G. D.: An overview of the HYSPLIT_4 modelling system for trajectories, dispersion, and deposition, Australian Meteorol. Mag., 47, 295-308, 1998.

Fernald, F. G.: Analysis of atmospheric lidar observations: some comments, Appl. Optics, 23, 652-653, doi:10.1364/AO.23.000652, 1984.

Fiebig, M.: Das troposphaerische Aerosol in mittleren Breiten Mikrophysik, Optik und Klimaantrieb am Beispiel der Feldstudie LACE 98, Ph.D., Fakultät für Physik, Ludwig-MaximiliansUniversität München, Oberpfaffenhofen, 259 pp., 2001.

Fiebig, M., Stohl, A., Wendisch, M., Eckhardt, S., and Petzold, A.: Dependence of solar radiative forcing of forest fire aerosol on ageing and state of mixture, Atmos. Chem. Phys., 3, 881-891, doi:10.5194/acp-3-881-2003, 2003.

Fromm, M., Bevilacqua, R., Servranckx, R., Rosen, J., Thayer, J. P., Herman, J., and Larko, D.: Pyro-cumulonimbus injection of smoke to the stratosphere: Observations and impact of a super blowup in northwestern Canada on 3-4 August 1998, J. Geophys. Res.-Atmos., 110, D08205, doi:10.1029/2004jd005350, 2005.

Fromm, M., Lindsey, D. T., Servranckx, R., Yue, G., Trickl, T., Sica, R., Doucet, P., and Godin-Beekmann, S. E.: THE UNTOLD STORY OF PYROCUMULONIMBUS, B. Am. Meteorol. Soc., 91, 1193-1209, doi:10.1175/2010bams3004.1, 2010.

Gao, R. S., Schwarz, J. P., Kelly, K. K., Fahey, D. W., Watts, L. A., Thompson, T. L., Spackman, J. R., Slowik, J. G., Cross, E. S., Han, J. H., Davidovits, P., Onasch, T. B., and Worsnop, D. R.: A novel method for estimating lightscattering properties of soot aerosols using a modified singleparticle soot photometer, Aerosol Sci. Tech., 41, 125-135, doi:10.1080/02786820601118398, 2007.

Groß, S., Esselborn, M., Weinzierl, B., Wirth, M., Fix, A., and Petzold, A.: Aerosol classification by airborne high spectral resolution lidar observations, Atmos. Chem. Phys., 13, 2487-2505, doi:10.5194/acp-13-2487-2013, 2013.

Haywood, J. M., Osborne, S. R., Francis, P. N., Keil, A., Formenti, P., Andreae, M. O., and Kaye, P. H.: The mean physical and optical properties of regional haze dominated by biomass burning aerosol measured from the C-130 aircraft during SAFARI 2000, J. Geophys. Res.-Atmos., 108, 8473, doi:10.1029/2002jd002226, 2003.

Hoose, C. and Möhler, O.: Heterogeneous ice nucleation on atmospheric aerosols: a review of results from laboratory experiments, Atmos. Chem. Phys., 12, 9817-9854, doi:10.5194/acp-12-98172012, 2012.

Jacobson, M. Z.: Strong radiative heating due to the mixing state of black carbon in atmospheric aerosols, Nature, 409, 695-697, doi:10.1038/35055518, 2001.

Jeßberger, P., Voigt, C., Schumann, U., Sölch, I., Schlager, H., Kaufmann, S., Petzold, A., Schäuble, D., and Gayet, J.-F.: Aircraft type influence on contrail properties, Atmos. Chem. Phys., 13, 11965-11984, doi:10.5194/acp-13-11965-2013, 2013.

Jost, H. J., Drdla, K., Stohl, A., Pfister, L., Loewenstein, M., Lopez, J. P., Hudson, P. K., Murphy, D. M., Cziczo, D. J., Fromm, M., Bui, T. P., Dean-Day, J., Gerbig, C., Mahoney, M. J., Richard, E. C., Spichtinger, N., Pittman, J. V., Weinstock, E. M., Wilson, J. C., and Xueref, I.: In-situ observations of mid-latitude forest fire plumes deep in the stratosphere, Geophys. Res. Lett., 31, L11101, doi:10.1029/2003g1019253, 2004.

Kahnert, M., Nousiainen, T., Lindqvist, H., and Ebert, M.: Optical properties of light absorbing carbon aggregates mixed with sulfate: assessment of different model geometries for climate forcing calculations, Opt. Express, 20, 10042-10058, doi:10.1364/OE.20.010042, 2012.

Klett, J. D.: Stable analytical inversion solution for processing lidar returns, Appl. Optics, 20, 211-220, doi:10.1364/ao.20.000211, 1981.

Knorr, W., Lehsten, V., and Arneth, A.: Determinants and predictability of global wildfire emissions, Atmos. Chem. Phys., 12, 6845-6861, doi:10.5194/acp-12-6845-2012, 2012.

Kondo, Y., Matsui, H., Moteki, N., Sahu, L., Takegawa, N., Kajino, M., Zhao, Y., Cubison, M. J., Jimenez, J. L., Vay, S., 
Diskin, G. S., Anderson, B., Wisthaler, A., Mikoviny, T., Fuelberg, H. E., Blake, D. R., Huey, G., Weinheimer, A. J., Knapp, D. J., and Brune, W. H.: Emissions of black carbon, organic, and inorganic aerosols from biomass burning in North America and Asia in 2008, J. Geophys. Res.-Atmos., 116, D08204, doi:10.1029/2010jd015152, 2011a.

Kondo, Y., Sahu, L., Moteki, N., Khan, F., Takegawa, N., Liu, X., Koike, M., and Miyakawa, T.: Consistency and Traceability of Black Carbon Measurements Made by Laser-Induced Incandescence, Thermal-Optical Transmittance, and Filter-Based Photo-Absorption Techniques, Aerosol Sci. Tech., 45, 295-312, doi:10.1080/02786826.2010.533215, 2011b.

Kübbeler, M., Hildebrandt, M., Meyer, J., Schiller, C., Hamburger, Th., Jurkat, T., Minikin, A., Petzold, A., Rautenhaus, M., Schlager, H., Schumann, U., Voigt, C., Spichtinger, P., Gayet, J.-F., Gourbeyre, C., and Krämer, M.: Thin and subvisible cirrus and contrails in a subsaturated environment, Atmos. Chem. Phys., 11, 5853-5865, doi:10.5194/acp-11-5853-2011, 2011.

Laborde, M., Mertes, P., Zieger, P., Dommen, J., Baltensperger, U., and Gysel, M.: Sensitivity of the Single Particle Soot Photometer to different black carbon types, Atmos. Meas. Tech., 5, 10311043, doi:10.5194/amt-5-1031-2012, 2012a.

Laborde, M., Schnaiter, M., Linke, C., Saathoff, H., Naumann, K.H., Möhler, O., Berlenz, S., Wagner, U., Taylor, J. W., Liu, D., Flynn, M., Allan, J. D., Coe, H., Heimerl, K., Dahlkötter, F., Weinzierl, B., Wollny, A. G., Zanatta, M., Cozic, J., Laj, P., Hitzenberger, R., Schwarz, J. P., and Gysel, M.: Single Particle Soot Photometer intercomparison at the AIDA chamber, Atmos. Meas. Tech., 5, 3077-3097, doi:10.5194/amt-5-3077-2012, 2012b.

Laborde, M., Crippa, M., Tritscher, T., Jurányi, Z., Decarlo, P. F., Temime-Roussel, B., Marchand, N., Eckhardt, S., Stohl, A., Baltensperger, U., Prévôt, A. S. H., Weingartner, E., and Gysel, M.: Black carbon physical properties and mixing state in the European megacity Paris, Atmos. Chem. Phys., 13, 5831-5856, doi:10.5194/acp-13-5831-2013, 2013.

Lee, D. S., Pitari, G., Grewe, V., Gierens, K., Penner, J. E., Petzold, A., Prather, M. J., Schumann, U., Bais, A., Berntsen, T., Iachetti, D., Lim, L. L., and Sausen, R.: Transport impacts on atmosphere and climate: Aviation, Atmos. Environ., 44, 46784734, doi:10.1016/j.atmosenv.2009.06.005, 2010.

Liu, D., Allan, J., Whitehead, J., Young, D., Flynn, M., Coe, H., McFiggans, G., Fleming, Z. L., and Bandy, B.: Ambient black carbon particle hygroscopic properties controlled by mixing state and composition, Atmos. Chem. Phys., 13, 2015-2029, doi:10.5194/acp-13-2015-2013, 2013.

Liu, L. and Mishchenko, M. I.: Scattering and radiative properties of complex soot and soot-containing aggregate particles, J. Quant. Spectrosc. Ra., 106, 262-273, doi:10.1016/j.jqsrt.2007.01.020, 2007

Mattis, I., Mueller, D., Ansmann, A., Wandinger, U., Preissler, J., Seifert, P., and Tesche, M.: Ten years of multiwavelength Raman lidar observations of free-tropospheric aerosol layers over central Europe: Geometrical properties and annual cycle, J. Geophys. Res.-Atmos., 113, D20202, doi:10.1029/2007jd009636, 2008.

McMeeking, G. R.: The optical, chemical, and physical properties of aerosols and gases emitted by the laboratory combustion of wildland fuels, Ph.D., Department of Atmospheric Sciences, Colorado State University, 321 pp., 2008.
McMeeking, G. R., Hamburger, T., Liu, D., Flynn, M., Morgan, W. T., Northway, M., Highwood, E. J., Krejci, R., Allan, J. D., Minikin, A., and Coe, H.: Black carbon measurements in the boundary layer over western and northern Europe, Atmos. Chem. Phys., 10, 9393-9414, doi:10.5194/acp-10-9393-2010, 2010.

McMeeking, G. R., Good, N., Petters, M. D., McFiggans, G., and Coe, H.: Influences on the fraction of hydrophobic and hydrophilic black carbon in the atmosphere, Atmos. Chem. Phys., 11, 5099-5112, doi:10.5194/acp-11-5099-2011, 2011.

Metcalf, A. R., Craven, J. S., Ensberg, J. J., Brioude, J., Angevine, W., Sorooshian, A., Duong, H. T., Jonsson, H. H., Flagan, R. C., and Seinfeld, J. H.: Black carbon aerosol over the Los Angeles Basin during CalNex, J. Geophys. Res.-Atmos., 117, D00V13, doi:10.1029/2011jd017255, 2012.

Mishchenko, M. I., Liu, L., Travis, L. D., and Lacis, A. A.: Scattering and radiative properties of semi-external versus external mixtures of different aerosol types, J. Quant. Spectrosc. Ra., 88, 139-147, doi:10.1016/j.jqsrt.2003.12.032, 2004.

Moosmüller, H., Chakrabarty, R. K., and Arnott, W. P.: Aerosol light absorption and its measurement: A review, J. Quant. Spectrosc. Ra., 110, 844-878, doi:10.1016/j.jqsrt.2009.02.035, 2009.

Moteki, N. and Kondo, Y.: Effects of mixing state on black carbon measurements by laser-induced incandescence, Aerosol Sci. Tech., 41, 398-417, doi:10.1080/02786820701199728, 2007.

Moteki, N. and Kondo, Y.: Dependence of Laser-Induced Incandescence on Physical Properties of Black Carbon Aerosols: Measurements and Theoretical Interpretation, Aerosol Sci. Tech., 44, 663-675, doi:10.1080/02786826.2010.484450, 2010.

Moteki, N., Kondo, Y., and Nakamura, S.: Method to measure refractive indices of small nonspherical particles: Application to black carbon particles, J. Aerosol Sci., 41, 513-521, doi:10.1016/j.jaerosci.2010.02.013, 2010.

Moteki, N., Kondo, Y., Oshima, N., Takegawa, N., Koike, M., Kita, K., Matsui, H., and Kajino, M.: Size dependence of wet removal of black carbon aerosols during transport from the boundary layer to the free troposphere, Geophys. Res. Lett., 39, L13802, doi:10.1029/2012gl052034, 2012.

Moteki, N., Kondo, Y., and Adachi, K.: Identification by singleparticle soot photometer of black carbon particles attached to other particles: Laboratory experiments and ground observations in Tokyo, J. Geophys. Res.-Atmos., 119, 1031-1043, doi:10.1002/2013jd020655, 2014.

Müller, D., Ansmann, A., Mattis, I., Tesche, M., Wandinger, U., Althausen, D., and Pisani, G.: Aerosol-type-dependent lidar ratios observed with Raman lidar, J. Geophys. Res.-Atmos., 112, D16202, doi:10.1029/2006jd008292, 2007.

Onasch, T. B., Trimborn, A., Fortner, E. C., Jayne, J. T., Kok, G. L., Williams, L. R., Davidovits, P., and Worsnop, D. R.: Soot Particle Aerosol Mass Spectrometer: Development, Validation, and Initial Application, Aerosol Sci. Tech., 46, 804-817, doi:10.1080/02786826.2012.663948, 2012.

Oshima, N., Kondo, Y., Moteki, N., Takegawa, N., Koike, M., Kita, K., Matsui, H., Kajino, M., Nakamura, H., Jung, J. S., and Kim, Y. J.: Wet removal of black carbon in Asian outflow: Aerosol Radiative Forcing in East Asia (A-FORCE) aircraft campaign, J. Geophys. Res.-Atmos., 117, D03204, doi:10.1029/2011jd016552, 2012.

Petzold, A., Weinzierl, B., Huntrieser, H., Stohl, A., Real, E., Cozic, J., Fiebig, M., Hendricks, J., Lauer, A., Law, K., Roiger, 
A., Schlager, H., and Weingartner, E.: Perturbation of the European free troposphere aerosol by North American forest fire plumes during the ICARTT-ITOP experiment in summer 2004, Atmos. Chem. Phys., 7, 5105-5127, doi:10.5194/acp-7-51052007, 2007.

Petzold, A., Veira, A., Mund, S., Esselborn, M., Kiemle, C., Weinzierl, B., Hamburger, T., Ehret, G., Lieke, K., and Kandler, K.: Mixing of mineral dust with urban pollution aerosol over Dakar (Senegal): impact on dust physico-chemical and radiative properties, Tellus B, 63, 619-634, doi:10.1111/j.16000889.2011.00547.x, 2011.

Petzold, A., Ogren, J. A., Fiebig, M., Laj, P., Li, S.-M., Baltensperger, U., Holzer-Popp, T., Kinne, S., Pappalardo, G., Sugimoto, N., Wehrli, C., Wiedensohler, A., and Zhang, X.-Y.: Recommendations for reporting "black carbon" measurements, Atmos. Chem. Phys., 13, 8365-8379, doi:10.5194/acp-13-83652013, 2013.

Posfai, M., Simonics, R., Li, J., Hobbs, P. V., and Buseck, P. R.: Individual aerosol particles from biomass burning in southern Africa: 1. Compositions and size distributions of carbonaceous particles, J. Geophys. Res.-Atmos., 108, 8483, doi:10.1029/2002jd002291, 2003.

Posfai, M., Gelencser, A., Simonics, R., Arato, K., Li, J., Hobbs, P. V., and Buseck, P. R.: Atmospheric tar balls: Particles from biomass and biofuel burning, J. Geophys. Res.-Atmos., 109, D06213, doi:10.1029/2003jd004169, 2004.

Pratt, K. A., Murphy, S. M., Subramanian, R., DeMott, P. J., Kok, G. L., Campos, T., Rogers, D. C., Prenni, A. J., Heymsfield, A. J., Seinfeld, J. H., and Prather, K. A.: Flight-based chemical characterization of biomass burning aerosols within two prescribed burn smoke plumes, Atmos. Chem. Phys., 11, 1254912565, doi:10.5194/acp-11-12549-2011, 2011.

Quennehen, B., Schwarzenboeck, A., Schmale, J., Schneider, J., Sodemann, H., Stohl, A., Ancellet, G., Crumeyrolle, S., and Law, K. S.: Physical and chemical properties of pollution aerosol particles transported from North America to Greenland as measured during the POLARCAT summer campaign, Atmos. Chem. Phys., 11, 10947-10963, doi:10.5194/acp-11-10947-2011, 2011.

Quennehen, B., Schwarzenboeck, A., Matsuki, A., Burkhart, J. F., Stohl, A., Ancellet, G., and Law, K. S.: Anthropogenic and forest fire pollution aerosol transported to the Arctic: observations from the POLARCAT-France spring campaign, Atmos. Chem. Phys., 12, 6437-6454, doi:10.5194/acp-12-6437-2012, 2012.

Ramanathan, V. and Carmichael, G.: Global and regional climate changes due to black carbon, Nat. Geosci., 1, 221-227, doi:10.1038/ngeo156, 2008.

Ramanathan, V. and Feng, Y.: Air pollution, greenhouse gases and climate change: Global and regional perspectives, Atmos. Environ., 43, 37-50, doi:10.1016/j.atmosenv.2008.09.063, 2009.

Real, E., Law, K. S., Weinzierl, B., Fiebig, M., Petzold, A., Wild, O., Methven, J., Arnold, S., Stohl, A., Huntrieser, H., Roiger, A., Schlager, H., Stewart, D., Avery, M., Sachse, G., Browell, E., Ferrare, R., and Blake, D.: Processes influencing ozone levels in Alaskan forest fire plumes during long-range transport over the North Atlantic, J. Geophys. Res.-Atmos., 112, D10S41, doi:10.1029/2006jd007576, 2007.

Rocadenbosch, F., Md Reba, M. N., Sicard, M., and Comerón, A.: Practical analytical backscatter error bars for elastic one- component lidar inversion algorithm, Appl. Optics, 49, 33803393, 10.1364/AO.49.003380, 2010.

Sahu, L. K., Kondo, Y., Moteki, N., Takegawa, N., Zhao, Y., Cubison, M. J., Jimenez, J. L., Vay, S., Diskin, G. S., Wisthaler, A., Mikoviny, T., Huey, L. G., Weinheimer, A. J., and Knapp, D. J.: Emission characteristics of black carbon in anthropogenic and biomass burning plumes over California during ARCTAS-CARB 2008, J. Geophys. Res.-Atmos., 117, D16302, doi:10.1029/2011jd017401, 2012.

Scarnato, B. V., Vahidinia, S., Richard, D. T., and Kirchstetter, T. W.: Effects of internal mixing and aggregate morphology on optical properties of black carbon using a discrete dipole approximation model, Atmos. Chem. Phys., 13, 5089-5101, doi:10.5194/acp-13-5089-2013, 2013.

Schumann, U., Mayer, B., Gierens, K., Unterstrasser, S., Jessberger, P., Petzold, A., Voigt, C., and Gayet, J. F.: Effective Radius of Ice Particles in Cirrus and Contrails, J. Atmos. Sci., 68, 300-321, doi:10.1175/2010jas3562.1, 2011a.

Schumann, U., Weinzierl, B., Reitebuch, O., Schlager, H., Minikin, A., Forster, C., Baumann, R., Sailer, T., Graf, K., Mannstein, H., Voigt, C., Rahm, S., Simmet, R., Scheibe, M., Lichtenstern, M., Stock, P., Rüba, H., Schäuble, D., Tafferner, A., Rautenhaus, M., Gerz, T., Ziereis, H., Krautstrunk, M., Mallaun, C., Gayet, J.F., Lieke, K., Kandler, K., Ebert, M., Weinbruch, S., Stohl, A., Gasteiger, J., Groß, S., Freudenthaler, V., Wiegner, M., Ansmann, A., Tesche, M., Olafsson, H., and Sturm, K.: Airborne observations of the Eyjafjalla volcano ash cloud over Europe during air space closure in April and May 2010, Atmos. Chem. Phys., 11, 2245-2279, doi:10.5194/acp-11-2245-2011, 2011 b.

Schumann, U., Jeßberger, P., and Voigt, C.: Contrail ice particles in aircraft wakes and their climatic importance, Geophys. Res. Lett., 40, 2867-2872, doi:10.1002/grl.50539, 2013.

Schwarz, J. P., Gao, R. S., Fahey, D. W., Thomson, D. S., Watts, L. A., Wilson, J. C., Reeves, J. M., Darbeheshti, M., Baumgardner, D. G., Kok, G. L., Chung, S. H., Schulz, M., Hendricks, J., Lauer, A., Karcher, B., Slowik, J. G., Rosenlof, K. H., Thompson, T. L., Langford, A. O., Loewenstein, M., and Aikin, K. C.: Single-particle measurements of midlatitude black carbon and light-scattering aerosols from the boundary layer to the lower stratosphere, J. Geophys. Res.-Atmos., 111, D16207, doi:10.1029/2006jd007076, 2006.

Schwarz, J. P., Gao, R. S., Spackman, J. R., Watts, L. A., Thomson, D. S., Fahey, D. W., Ryerson, T. B., Peischl, J., Holloway, J. S., Trainer, M., Frost, G. J., Baynard, T., Lack, D. A., de Gouw, J. A., Warneke, C., and Del Negro, L. A.: Measurement of the mixing state, mass, and optical size of individual black carbon particles in urban and biomass burning emissions, Geophys. Res. Lett., 35, L13810, doi:10.1029/2008g1033968, 2008a.

Schwarz, J. P., Spackman, J. R., Fahey, D. W., Gao, R. S., Lohmann, U., Stier, P., Watts, L. A., Thomson, D. S., Lack, D. A., Pfister, L., Mahoney, M. J., Baumgardner, D., Wilson, J. C., and Reeves, J. M.: Coatings and their enhancement of black carbon light absorption in the tropical atmosphere, J. Geophys. Res.-Atmos., 113, D03203 doi:10.1029/2007jd009042, 2008 b.

Schwarz, J. P., Spackman, J. R., Gao, R. S., Watts, L. A., Stier, P., Schulz, M., Davis, S. M., Wofsy, S. C., and Fahey, D. W.: Global-scale black carbon profiles observed in the remote atmosphere and compared to models, Geophys. Res. Lett., 37, L18812, doi:10.1029/2010g1046007, 2010. 
Sedlacek III, A. J., Lewis, E. R., Kleinman, L., Xu, J., and Zhang, Q.: Determination of and evidence for non-core-shell structure of particles containing black carbon using the Single-Particle Soot Photometer (SP2), Geophys. Res. Lett., 39, L06802, doi:10.1029/2012g1050905, 2012.

Shiraiwa, M., Kondo, Y., Iwamoto, T., and Kita, K.: Amplification of Light Absorption of Black Carbon by Organic Coating, Aerosol Sci. Tech., 44, 46-54, doi:10.1080/02786820903357686, 2010.

Stephens, M., Turner, N., and Sandberg, J.: Particle identification by laser-induced incandescence in a solid-state laser cavity, Appl. Optics, 42, 3726-3736, doi:10.1364/AO.42.003726, 2003.

Tesche, M., Ansmann, A., Mueller, D., Althausen, D., Engelmann, R., Freudenthaler, V., and Gross, S.: Vertically resolved separation of dust and smoke over Cape Verde using multiwavelength Raman and polarization lidars during Saharan Mineral Dust Experiment 2008, J. Geophys. Res.-Atmos., 114, D13202, doi:10.1029/2009jd011862, 2009.

Tesche, M., Mueller, D., Gross, S., Ansmann, A., Althausen, D., Freudenthaler, V., Weinzierl, B., Veira, A., and Petzold, A.: Optical and microphysical properties of smoke over Cape Verde inferred from multiwavelength lidar measurements, Tellus B, 63, 677-694, doi:10.1111/j.1600-0889.2011.00549.x, 2011.

Voigt, C., Schumann, U., Jurkat, T., Schäuble, D., Schlager, H., Petzold, A., Gayet, J.-F., Krämer, M., Schneider, J., Borrmann, S., Schmale, J., Jessberger, P., Hamburger, T., Lichtenstern, M., Scheibe, M., Gourbeyre, C., Meyer, J., Kübbeler, M., Frey, W., Kalesse, H., Butler, T., Lawrence, M. G., Holzäpfel, F., Arnold, F., Wendisch, M., Döpelheuer, A., Gottschaldt, K., Baumann, R., Zöger, M., Sölch, I., Rautenhaus, M., and Dörnbrack, A.: In-situ observations of young contrails - overview and selected results from the CONCERT campaign, Atmos. Chem. Phys., 10, 9039 9056, doi:10.5194/acp-10-9039-2010, 2010.

Voigt, C., Schumann, U., Jessberger, P., Jurkat, T., Petzold, A., Gayet, J. F., Kraemer, M., Thornberry, T., and Fahey, D. W.: Extinction and optical depth of contrails, Geophys. Res. Lett., 38, L11806, doi:10.1029/2011g1047189, 2011.
Voigt, C., Jessberger, P., Jurkat, T., Kaufmann, S., Baumann, R., Schlager, H., Bobrowski, N., Giuffrida, G., and Salerno, G.: Evolution of $\mathrm{CO}_{2}, \mathrm{SO}_{2}, \mathrm{HCl}$ and $\mathrm{HNO}_{3}$ in the volcanic plumes from Etna, Geophys. Res. Lett., 41, 2196-2203, doi:10.1002/2013g1058974, 2014.

Weinzierl, B., Petzold, A., Esselborn, M., Wirth, M., Rasp, K., Kandler, K., Schuetz, L., Koepke, P., and Fiebig, M.: Airborne measurements of dust layer properties, particle size distribution and mixing state of Saharan dust during SAMUM 2006, Tellus B, 61, 96-117, doi:10.1111/j.1600-0889.2008.00392.x, 2009.

Weinzierl, B., Sauer, D., Esselborn, M., Petzold, A., Veira, A., Rose, M., Mund, S., Wirth, M., Ansmann, A., Tesche, M., Gross, S., and Freudenthaler, V.: Microphysical and optical properties of dust and tropical biomass burning aerosol layers in the Cape Verde region-an overview of the airborne in situ and lidar measurements during SAMUM-2, Tellus B, 63, 589-618, doi:10.1111/j.1600-0889.2011.00566.x, 2011.

Weinzierl, B., Sauer, D., Minikin, A., Reitebuch, O., Dahlkoetter, F., Mayer, B., Emde, C., Tegen, I., Gasteiger, J., Petzold, A., Veira, A., Kueppers, U., and Schumann, U.: On the visibility of airborne volcanic ash and mineral dust from the pilot's perspective in flight, Phys. Chem. Earth, 45-46, 87-102, doi:10.1016/j.pce.2012.04.003, 2012.

Wendisch, M., Coe, H., Baumgardner, D., Brenguier, J.-L., Dreiling, V., Fiebig, M., Formenti, P., Hermann, M., Krämer, M. Levin, Z., Maser, R., Mathieu, E., Nacass, P., Noone, K., Osborne, S., Schneider, J., Schütz, L., Schwarzenböck, A., Stratmann, F., and Wilson, J. C.: Aircraft Particle Inlets: State-of-theArt and Future Needs, American Meteorological Society, 85, 8991, doi:10.1175/BAMS-85-1-89, 2004.

Wiedinmyer, C., Akagi, S. K., Yokelson, R. J., Emmons, L. K., AlSaadi, J. A., Orlando, J. J., and Soja, A. J.: The Fire INventory from NCAR (FINN): a high resolution global model to estimate the emissions from open burning, Geosci. Model Dev., 4, 625641, doi:10.5194/gmd-4-625-2011, 2011. 